\title{
XIV.
}

\section{Auffassung und Analyse des Menschen im 15. und 16. Jahrhundert.}

Von

Wilhelm Dilthey in Berlin.

Zweite Hälfte.

Die humanistische Bewegung in Italien gehörte den Städten, den Höfen und den oberen Ständen an. Ihre ungestörte Entfaltung hatte den Charakter des Papstthums von Alexander VI, Julius II. und Leo X. zur Voraussetzung. Und die Gegenreformation erwies, dass sie die Tiefe und Breite der Nation nicht ergriffen hatte. Langsam, zähe, die Nationen in ihrer letzten Tiefe erfassend trat nun im Norden Europas bei den germanischen Völkern die reformatorische Bewegung hervor, welche durch die Befreiung ron der römischen Priesterherrschaft die äusseren Bedingungen einer unabhängigen wissenschaftlichen Bewegung schuf, durch die Verlegung des Rechtsgrundes der Dogmen in die religiös sittliche Innerlichkeit die Ausbildung einer kritischen Theologie ormöglichte and in ihrem Verlaufe die moralische und religiöse Autonomie der Person zur Grandlage des geistigen Lebens bei uns machen sollte.

Deutschland, ron dem diese Bewegung ausging, war damals in einer aufsteigenden Entwicklung seiner Volkskraft und scines Reichthums, der Industrie und des Handels. Seitdem Konstantinopel aufgehört hatte, den Ausgangspunkt der grossen Verkehrsbahnen nach dem Norden zu bilden, ging der llandel von Italien über die gangbar gemachten Alpenpässe, dann über Deutachland 
nach der Nord- und Ostsee: nun blühten die deutschen Städte empor. Aus den Grubenwerken vom Erzgebirg und Harz warde ein Reichthum von Edelmetallen heraufbefördert, der mehr noch als die 'Zufuhr aus den amerikanischen Gold- und Silberminen die Preisrevolutionen im zweiten Jahrzehnt des 16. Jahrhunderts hervorrief. Hierzu kam, was Macchiavelli 1508 als Hauptgrund für den steigenden deutschen Reichthum hervorhob, die Fortdauer verhältnissmässig einfacher und genügsamer Sitten. „Sie bauen nicht, .sie machen für Kleider nicht Aufwand, sie verwenden auf Hausgeräthe nichts; ihnen genügt, Ueberfluss an Brod und Fleisch und eine geheizte Stube zu haben ${ }^{1}$ ). “ Der deutsche Kaufmann war jetzt auf allen Märkten. Die Augsburger Weltfirmen hatten an allen grossen Plätzen ihre Vertreter. Die strotzende Volkskraft drängte in Kolonisationen und Kriegsdiensten überall hin nach aussen. So erwuchsen nun in diesem noch uncentralisirten Volke, das durch den Gegensatz von Städten, Rittern, Fürsten und Kaiser zu keiner einheitlichen politischen Aktion fähig war, selbständige Mittelpunkte geistiger Bildung ohne Zahl: ein Ueberschwang drängender geistiger Kräfte war da: aus der zunehmenden Verbindung mit Italien entstand ein Zuströmen italienischer Kunstübung und humanistischer Schriften.

Dies ganze Land aber war überzogen von einem Netz kirchlicher Machtwirkungen, die schliesslich alle in Rom ihr Centrum hatten. Das Bild einer Stadt jener Tage zeigt ringsum starke Thore, Gräben und Festungswerke, innen aber die weithin herrschenden Thürme, die Portale mit hochragenden Giebeln und die weitgestreckten Baumassen von Domen, Kirchen und Klöstern. So war auch das geistige Leben der da drinnen eingezwängten Menschen von den festen kirchlichen Begriffen beherrscht. Der Mensch kann sich von der Sinnenlust, der Sünde, dem Teufel und den ewigen Strafen nur durch die geregelte Hilfe der Kirche, durch das genau geordnete System von Sakramenten, Ohrenbeichte, Bussen und frommen Werken lösen; ja über seinen Tod hinaus reichen die religiösen Pflichten der Seinen, ihn aus dem Fegefeuer zu befreien. In diesen Stufengang von Beichte, Sakrament, Ablass, Opfer und

1) So in Macchiavelli's Bericht,über Deutschland vom'Juni 1508. 
äusseren Werken hatte sich nun der ganze Tiefsinn der Mystik und der franziskanischen Nachfolge Christi ergossen. Auch waien noch die wissenschaftlichen Begriffe von der Natur in einem gerrissen Einklang mit dieser kirchlichen Disciplin. Noch war das Wirken der Natur für den Naturforscher schliesslich aus dem Wirken geistiger Kräfte in ihr zusammengesetzt. Magische Kraftwirkungen wurden auch von hervorragenden Naturphilosophen angenommen. Dem starken Gebetsglauben entsprach als die dunklo Seite dieser Weltauffassung der Teufels- und Hexenglaube. Ebenso bestand noch keine methodisch begründete historische Kritik gegenüber der Summe kirchlicher Traditionen. Es geschahen im Volke plötzliche Ausbrüche ron Angst vor diesen überall eingreifenden jenseitigen Kräften, in den Kirchen gab es blutschwitzende Hostien, am Himmel blutige Kreuze und Lanzen, in Stadt und Land eine unermessliche Zahl von Wallfahrern, Flagellanten und Propheten, wunderthätigen Marienbildern und Busspredigern. Man konnte sich im Bauen ron neuen Kirchen und Kapellen, sowie in deren Ausschmückung nicht genugthun. Alle diese Einwirkungen des kirchlichen Systems waren nun aber schliesslich wie mit eisernen Klammern in die Verfassung des deutschen Reiches eingefügt.

So ist es gekommen, dass in den deutschredenden Ländern die in Earopa ron Land zu Land sich fortplanzende geistigo Beregung einen religiōsen Ausdruck erhielt. Und eben darum führte die immer zunehmende, ungeheure religiöse Spannung, die in der ganzen römiscben Kirche lange bestand und beständig wuchs, hier zu einer Explosion. Der Fortgang der Civilisation, der Erfindungen, Entdeckungen und Industrie batte während des 15. Jahrhunderts mit dem Nominalismus zusammengewirkt, welcher der Todtengräber der alten rationalen Theologie gewesen ist. Die theologische Metaphysik des Nittelalters lüste sich auf. Eben hierdurch war nun aber innerhalb- der kirchlichen Organisation und ihrer Personen die Bebandlung des Dogmas als einer Rechtsordnung und die Verstärkung und Ausnützang des kirchlichen Apparates, kurz der Kurialismus, verstärt worden. Dieser äussere Druck auf die lebendigen religiösen Kräfte hatte aus dem unter dem Boden heimlich glimmenden Seltenglauben das Feuer der Hussitenbewegung auffammen 
lassen. Auch die kirchliche Aristokratie hatte ihrerseits, vergebens freilich, in den drei grossen-Concilien des 15. Jahrhunderts den Kampf mit dem Kurialismus aufgenommen und eine Reform der Kirche an Haupt und Gliedern angestrebt. War hiernach der Ruf nach Reform allgemein, so entfaltete sich auch bereits der Kern des Neuen. In der praktischen Mystik war zum Mittelpunkt von Religion und Theologie der innere Process geworden, durch welchen die Einzelperson aus dem Ringen mit ihren Affekten und mit ihren Leiden zum inneren Frieden gelangt. Von Bradwardina und dem vierzehnten Jahrhundert ab hatte man zugleich zum Augustinismus zurückgegriffen, welcher so nun zum zweiten Male das metaphysische Schauspiel der Trinität und Menschwerdung dem friedebedürftigen Menschenherzen näher zu bringen versuchen sollte. Ein Auskunftsmittel auf Zeit. Aber definitiv war die Verlegung des religiösen Interesse aus dem kosmischen Drama in das persönliche Verhältniss zu dem Christus mit den leidensvollen Zügen und zu dem traulicher und näher gefühlten Gottvater. Dies spricht auch aus den Bildern von Giovanni Bellini und Perugino, von Rogier van der Weyden und Memling, aus den Todtentänzen und Stationsbildern dieses fünfzehnten und anhebenden sechszehnten Jahrhunderts, wie aus dessen Predigten. Wohl war die Kurie klug bestrebt, diese Verschiebung des religiösen Interesse äusserlich zu nutzen: innerlich ihm genugzuthun vermochte sie nicht.

Unter diesen Bedingungen wandte sich die Bewegung in den Ländern deutscher Zunge den religiösen und theologischen Problemén zu. Wir betrachten die Bewegung der Reformation, die so entstand, nicht unter dem kirchen- oder dogmenhistorischen Gesichtspunkt, wir verfolgen nicht, wie neue Kirchen sich nun bildeten und Veränderungen im Bestande der christlichen Dogmen eintraten, sondern wir versuchen, diese Bewegung als ein hochwichtiges Glied.in der Verkettung der geistigen Vorgänge des 16. Jahrhunderts aufzufassen. Wir möchten erkennen, wie die Menschheit aus der theologischen Metaphysik des Mittelalters so dem 17. Jahrhunderts, der Begründung der Herrschaft des Menschen über die Natur, der Autonomie des erkennenden und handelnden Menschen, der Ausbildung eines natürlichen Systems auf dem Gebiet von Recht und 
Staat, Kunst, Moral und Theologie entgegengeschritten ist. Ilier ist besonders wichtig, wio ein religiös universaler Theismus am Beginn des 16. Jahrhunderts in ganz Europa siegreich hervordrang, wie sich ihm Luther entgegenwarf, wie dieser Standpunkt aber von Zwingli in gewissen Grenzen aufgenommen und von den Sekten, zumal denen der reformirten Kirche fortgebildet worden ist: mit diesen Sekten und dem reformirten Geiste steht dann an den meisten Stellen die Fortgestaltung dieses Standpunktes währond des 17. Jahrhunderts in klar erkennbarem historischem Zusammenhang. Nicht minder bedeutend ist, wie ein neues Lebensideal aus der veränderten Lage der Gesellschaft entsteht, nach welchem das Individuum scinen innerlichen, sellständigen Werth fühlt und dessen Entfaltung frohmüthig im Wirken innerhalb der concreten Lebensverhältnisse sucht, wie Luther und Zwingli diesem Lebensideal in dem kirchlichen Leben selber Raum und Freiheit schaffen, wie auch hier nur schwer gegenüber den Ueberlieferungen das Neuc sich durchringt. Wir möchten dann verstehen, wie in den Menschen dieser Reformationszeit, unterschieden von den mittelalterlichen Köpfen und ihrer theologischen Metaphysik, eine neue Art, die höheren Ueberzeugungen über das Verhältniss des Menschen zum Unsichtbaren zu befestigen und zu begründen aufgetreten ist. Wir möchten das Verhältniss dieser Ideen zu der Gesellschaft in seinem Ursprung erfassen: ein Verhältniss, von welchem beinahe zwei Jahrhunderte hindurch alle Veränderungen der europäischen Gesellschaft mitbedingt gewesen sind. Dann ein Letztes. Hier liegt nun auch der Anfang einer Theologie von neuem Charakter: losgelöst von den scholastischen Speculationen, auf das Erfahrbare gegründet, auf den erlebten religiösen Vorgang und auf die christliche Literatur. Denn in der inneren Erfahrung und in der kritischen Geschichto des Christenthums hat bis auf unseren Tag diese neue Theologie ihre Grundlagen gehabt. Durch sie ist erst allmälig eine alle Instanzen berücksichtigende Einsicht in die sittliche Autonomic des Menschen errungen worden.

Erasmus, der Voltaire des 16. Jahrbunderts, hat cin Menschenalter hindurch die Geister beherrscht und die antikirchlicho Be- 
wegung geleitet. Von seiner Geburt ab war ihm Unglück und Druck von den Mönchen gekommen: dann hatte er dieselben im Kloster gründlich kennen und hassen gelernt. Er wandte sich der aufgehenden Sonne der humanistischen Wissenschaft zu und fühlte im Fortschroiten bald, dass er zum Schriftsteller geboren war. Alle Formen wandte er an, Poesie und Prosa, Dialog, Abhandlung und Brief, überall flüchtig, ein Improvisator; aber jedes seiner Werke ist erfüllt von dem Gefühl dessen, was die Zeit bedurfte. Wie er das neue Latein der Humanisten gebrauchte, ohne Pedanterie, mit unvergleichlichem Sprachgefühl, schmiegte sich diese Weltsprache allen Ideen und Stimmungen der Zeit an. Alles klang in ihm an, was die Zeit Widersprechendes hegte: die Neigung einer überkräftigen, männlichen Generation zum derben Scherz über die Sinnlichkeit, die Freude am Sonnenaufgang der-Wissenschaften, der Hass eines ganz unabhängigen Geistes gegen die Kirchen und doch die ernstgemeinte Vertiefung in die theologischen Probleme der Zeit: er war wie ein Dämon mit hundert Angesichtern von ganz verschiedenem Ausdruck und Mienenspiel: und gerade deswegen hafteten an ihm fragend, zweifelnd, bezaubert die Augen der Zeitgenossen. Ein unermessliches Verdienst erwarb er sich durch sein Eintreten für die religiöse Toleranz; es war das eigenste Wesen des zarten, kleinen, immer kränkelnden Mannes mit den halbgeschlossenen blauen beobachtenden Augen, als einzige Waffe im religiösen Streite das Wort anzuerkennen. In politischen Dingen verfocht er die liberalen Ideen der Zeit. Darin lag nun aber das Philosophische und Universelle dieser Natur, dass sie der Prüfung des Denkens Alles unterwarf. Die Freude des selbstgewissen Intellektes an seiner Souveränität durchleuchtet in übermüthigem Witz wie in gelehrtem kritischem Ernst seine ganze Person. Den höchsten Ausdruck findet. dies sein Lebensgefühl in seinem genialsten und wirksamsten. Werke, dem „Lob der Narrheit". In diesem erhebt sich Erasmus über seine Vorbilder zu wahrem Humor. Er stellt die Seite des Lebens dar; in welcher leicht eine gute Portion Narrheit gefunden werden kann, Liebe, Fortpflanzung, Heroismus, und ohne welche doch alles höchst Verständige in dieser Welt gar nicht da wäre oder nicht bestehen 
könnte. Dies thut er in wahrhaft humoristischer Einkleidung. Frau Narrheit hält eine Lobrede auf sich selbst, und ihre Zuhörer sind auch lauter Narron. Alle Schwächen der Zeit, zumal der Kircho und der Wissenschaften, werden in beispielloser Kühnheit vor das Gericht des Verstandes und Witzes gezogen. Bald leichtfertig, bald schwermüthig spricht diese Schrift das Gefühl von der Zweideutigkeit des Lebens aus. Eine Stimmung, welche gleich der Petrarca's so noch vou keinem Modernen geltend gemacht worden war. Lucian ist freilich der Lehrmeister des Erasmus gewesen. Wie reizend ist dann auch mancher Scherz in den Colloquien: man lese den Dialog zwischen einem Jüngling und einem Mädchen, das ins Kloster will. Und nun ward doch auch diesem Voltaire des 16. Jahrhunderts das grosse Problem der Zeit, das wahre Christenthum, zum Mittelpunkt seiner kritischen Operationen. Er wollte das reine Evangelium erfassen. Dieser Aufgabe der Zeit diente seine wichtigste wissenschaftliche Arbeit, die Edition des neuen Testaments; dann die nach Valla's Vorgang auf historisch-kritisches Verständniss gerichteten Annotationen zum neuen Testament und Paraphrasen zu den Briefen und zu den Evangelien des Matthaeus und Johannes; ebenso seine patristischen Leistungen: Anfänge einer Patrologie. Mit all diesen gelehrten Hilfsmitteln suchte er nun aber vorzudringen bis zu „der Philosophie Christi". Die Seele, sagt er im Enchiridion, ihres himmlischen Ursprungs eingedenk, ringt mit der irdischen Stofflichkeit. Und hierbei kommt ihr nun aus dem Glauben Unterstützung, der eben darin besteht, dass sie sich Christus als Ziel vorhält. „Christum vero esse puta non rocem inanem, sed nihil aliud quam charitatem, simplicitatem, patientiam, puritatem, breviter quidquid ille docuit $\left.{ }^{3}\right)$. Und diese einfache Philosophie Christi ist ilım mit der des Cicero, Seneca und Plato im Einklang. Auch sie haben unter dem Einfluss göttlicher Inspiration geschrieben. Cicero war von

7 Ito Enchiridion Opp. ed. Cleric. V 25. Vergl. die Schilderung des vulgären Glaubens im Encomion Sloriae Opp. IV 443, sowie die kundige Darstellung des Verlaufs, in dem die einfache Philosophie Christi zu dem kirchlichen System und Apparat ausgewachsen ist, in Annot. ad Mattb. 11, 30, zu den Worten: jugum meum suave. Schon bei Erasmus trith das Streben nach Simplifikation berror, das dann luther leitet. 
der Gottheit beseelt. So vertritt schon Erasmus die Lehre von einer Offenbarung oder Inspiration in den edelsten Römern und Griechen. Zugleich hat auch er schon stark empfundẻn, wieviel Räthselhaftes die biblischen Schriften enthalten, ja wie das alte Testament auch von Anstössigem nicht frei sei. Hier greift er zu dem bereitliegenden Hilfsmittel, wie in den mythologischen Fabeln der Griechen, so auch in den heiligen Schriften Allegorien anzuerkennen. Nähme er die Bücher der Richter oder der Könige wörtlich, so müsste er ihnen den Livius vorziehen. Und zwar sind ihm nicht nur Erzählungen wie der Sündenfall mit seinem Apfel und seiner Schlange Allegorien. In den altchristlichen Vorstellungen selber erkennt er ein Element des Symbolischen an. „Nec alia est flamma, in qua cruciatur dives ille commissator evangelicus; nec alia supplicia inferorum .. quam perpetua mentis anxietas, quae peccandi consuetudinem comitatur."

Nicht ein grosser Schriftsteller, aber ein concentrirt arbeitender Gelehrter, hat dann Reuchlin neben Erasmus an der neuen, auf die Urkunden des Christenthums selbst gegründeten Theologie mitgearbeitet. Besonders indem seine rudimenta hebraica das erste vollständige Lehrgebäude der hebräischen Sprache gaben. „Es ist vor mir keiner gewesen, der sich unterstanden, hätte, die Regeln der hebräischen Sprache in ein Buch zu bringen, und sollte dem Neide sein Herz zerbrechen, dennoch bin ich der Erste. Exegi monumentum aere perennius ${ }^{3}$ )." An vielen Stellen seines Werkes wies er der Vulgata ihre Sprachschnitzer nach.

Aber die von Italien beeinflussten Humanisten in Deutschland sind weit über die Grenzen, welche Erasmus seinen öffentlichen Aeusserungen zog, hinausgeschritten.

Schon Erasmus und Reuchlin sind von dem religiös universalistischen Theismus der italienischen Humanisten stark beeinflusst. Unter diesem verstehe ich die Ueberzeugung, dass die Gottheit in den verschiedenen Religionen und Philosophien gleicherweise wirksam gewesen sei und noch heute wirke. In dem mo-

3) Hardt, Historia Ref. p. 49 in Reuchlini Consilium pro libris Judaeorum non abolendis. 
ralisch religiösen Bewusstsein jedes edleren Monschen spreche sic sich aus. Ein Satz, der dio Idee eines völlig universellen Wirkens der Gottheit durch die ganze Natur hindurch und in dem höheren Bewusstsein aller Menschen zu seiner Voraussetzung hat. So wird er in der Regel mit einer pantheistischen oder panenthoistischen Auffassung der Weltordnung verbunden sein. Wie eine solche damals neben der nominalistischen sehr verbreitet war, angelehnt an Platonismus, Stoa und christliche Mystik.

Dieser religiös universalistische Theismus ist aus der Vergleichung der religiös sittlichen Lebenshaltung innerhalb der verschiedenen Religionen bei scharfsinnigen mittelalterlichen Beobachtern entstanden, sonach aus dem Leben selbst und seiner unbefangenen Bctrachtung. Die Grundlinien derselben wurden schon in dem Bildungskreise des Staufers Friedrich II. gezogen. . In Saladin erblickten schon Boccaccio und andere italienische Novellisten ein Ideal von Stolz, Würde und Edelmuth. In der Erzählung von den drei Ringen ist dieser religiös neutrale Theismus ausgesprochen. In der epischen Poesie der Italiener, welche die Kämpfe zwischen Christen und Muhamedanern verherrlicht, liessen die Dichter öfters Muhamedaner oder die Dämonen einer ausserchristlichen Region aussprechen, was sie nicht in eigner Person hätten aussprechen mögen. So legt Pulci dem Dämon Astarott Betrachtungen über den relativen Werth der Religionen in den Mund. Derselbe Standpunkt ward dann während des fünfzehnten Jahrhunderts aus dem humanistischen Studium der Classiker abgeleitet. Hierbei wirkte die Verehrung der moralischen Grösse der Alten zusammen mit der Aneignung ihres seit der Stoa entwickelten universellen Theismus. Waren doch Cicero's und Seneca's Schriften, in welchen dieser höchste vom Alterthum erreichte Standpunkt ausgedrüclt war, die tägliche Nahrung der Humanisten und der ihnen befreundeten gebildeten Italiencr. Georgios Gemistos Plethon, der bei dem Concil in Ferrara und Florenz in der Mitte des fünfzehnten Jahrhunderts verweilte, ist religionsgeschichtlich eine sehr wichtige Persönlichkeit. Der still verfolgte $\mathrm{Z}$ weck scines Lebens war die Begründung eines religiös universalistischen Theismus als einer neuen, rom Christenthum unterschiedenen Religion. Den Stoff gab ihm Plato, dic Samen für Gott und dic 
göttlichen Kräfte entlehnte er seiner heimischen altgriechischen Mythologie mit Verschmähung der christlichen Bezeichnungen: in so klarer Strenge schied er diesen neuen Glauben von dem christlichen "). Dieser in mannichfachen Anpassungen an das Christenthum nun in der platonischen Akademie von Florenż vertretene religiös universalistische Theismus hat seinen vollkommensten Ausdruck in den Hymnen des Lorenzo magnifico gefunden.' Von' ihnen sind Michel Angelo's Dichtungen beeinflusst. Nach der Ansicht von Jacob Burckhardt war dieser Theismus in den gebildeten italienischen Kreisen jener Tage weit verbreitet. Ihm kam die historische Kritik in der neuen Schule entgegen. Lorenzo Valla bestritt die. Echtheit des Briefes von Abgarus an Christus, die Abfassung des apostolischen Symbolums durch alle Apostel, bezeichnete Moses und die Evangelisten als blosse Historiker und zerstörte definitiv die Fabel von der Constantinischen Schenkung. Von einem Bologneser Arzte wurde 1498 vor der Inquisition festgestellt, dass er Christus als natürlich empfangen und mit Recht zum Kreuzestod verurtheilt betrachtete ${ }^{5}$ ).

Diese Verbindung eines religiös universellen Theismus mit philologischer, theilweise ganz radicaler Kritik der Quellen des Christenthums finden wir nun auch in dem Kreise der Erfurter Humanisten. In sie mischen sich auch hier ein ungestüm lodernder Hass gegen die Mönche, die kirchliche Disciplin und die scholastische Metaphysik, wie er die Italiener und den Erasmus gleichmässig beseelte, und laxe moralische Begriffe, wie sie aus anerzogener Mönchsmoral zusammen mit deren nachträglicher Verwerfung entstehen mussten.

Das geistige Haupt dieser Richtung war der Erfurter Kanoniker Konrad Mudt (Mutianus Rufus). Er war früh nach Italien gegangen; dort war er von dem religiös universalistischèn Theismus, in der besonderen neuplatonischen Form desselben bei Pico und Marsilio Ficino, ergriffen worden, wie denn auch andere hervorragende

4) Diese Stellung des Plethon hat Fritz Schultze im ersten Bande seiner Geschichte der Renaissance (1874), der Plethon und seine reformatorischen Bestrebungen behandelt, aufgezeigt.

5) Jacob Burckhardt, Renaissance II $299 \mathrm{ff}$. 
Theologen deutscher. Zunge, unter Anderen Reuchlin und Zwingli von diesem stark beeinflusst worden sind. Nun sass or in seinem Hause hinter der Domkirche zu Gotha in literarischer Friedseligkeit. Ueber dem Eingang stand dio Inschrift: beata tranquillitas; innen forderte eine zweite: bonis cuncta pateant, zur Selbstprüfung die Eintretenden auf.. Als ihm in dio geliebte Bücherei des Hauses einmal zugleich mehrere schöne Editionen alter Autoren. kamen, ist er in Freudenthränen ausgebrochen. Wio er jeder Berufung zu grösserer Wirksamkeit widerstand, so hat er auch nichts veröffentlicht. Aber eine starke Wirkung ging von dieser imponirenden Persönlichkeit nach der nahen Erfurter Universität und weiter in die Ferne durch eine wahrhaft Gleim'sche Gastfreundschaft und durch einen geistreichen, lebhaften Briefwechsel aus. Diese Briefe allein unterrichten uns heute über scine Ansichten. Die grosse religiös universalistische Lehre der italienischen Neuplatoniker von dem unsichtbaren Logos als Träger aller Offenbarungen und Philosophien in der Menschheit verbindet sich auch in diesem stillen Denker mit der zunehmenden philologischen Kritik, die nun auf die altchristlichen Quellen sich erstreckte. In dem berühmten Briefe an Spalatin löst er die Fragen, die sich an die dogmatische Vorstellung von der langandauernden Finsterniss der Heidenwelt bis zu Christi Erscheinen knüpfen ${ }^{6}$ ), durch die Lehre von der allgemeinen Offenbarung, d. h. die göttliche Beseelung der ganzen Menschheit. Der wahre Christus ist unsichtbar und zu allen Zeiten wie an allen Orten gegenwärtig: die Weisheit Gottes; diese ist nicht blos bei den Juden in einem Winkel Syriens, sondern überall und zu allen Zeiten, bei Griechen, Römern und Germanen wirksam gewesen. Und zwar denkt er sich nun eine Verbreitung der göttlichen Weisheit über die theistischen Religionen und Philosophien der Kulturvölker hin-

7 Gerson Opp. III p. 1585 eræâhnt schon als einen Gegenstand der Debatte, der den Weltleuten ganz gelâufig war, warum Gott nicht lieber, statt Einige zu erwäblen, Alle gerettet hätte. Rulman Herswin in dem Buch von den neun Felsen 1352 bat folgendes Gexpräch 2 kischen einem Venschen und ciner ibn ermabnenden Stimme: ,Dass Du sprichst, dass das brise jüdische Vulk und das bige heidnische Volk als verloren solle werden, das ist nicht wabr". Der Sensch: "Ach, wie scheint wir das cine ko fremdartige hede"s Aebalich Christoph Fürer bei Lochner S. 59 . 
aus bis in die Mythologien. Dem innigbefreundeten. Cistercienserpater Heinrich Urban vertraut, er, als ein Letztes, folgende Lehre an. „Es ist Ein Gott und Eine Göttin. Aber wie viele Gestalten, so sind auch viele Namen: Jupiter, Sol, Apollo, Moses, Christus, Luna, Ceres, Proserpina, Tellus, Maria. Doch hüte dich dies auszuplaudern. Es muss in Schweigen gehüllt werden, wie die Mysterien der Eleusinischen Göttinnen. In Religionssachen muss man sich der Decke von Fabeln und Räthseln bedienen. Du, mit Vergunst von Jupiter, nämlich dem besten und grössten Gotte, verachte schweigend die kleinen Götter. Sage ich Jupiter,' so meine ich Christius und den wahren Gott ${ }^{7}$ ). " Aus diesem religiös universalistischen Theismus ergab sich ihm, wie seinem Cicero, die Existenz eines natürlichen Sittengesetzes, das durch den höchsten Lehrer in unsre Seelen eingegossen ist. Dagegen verurtheilte er die ganze kirchliche Sittendisciplin, Bettelmönche, Fastenspeisen, Ohrenbeichte, Seelenmessen. Und über die heiligen Schriften liess er zuweilen Andeutungen von höchst verwegenen kritischen Hypothesen vernehmen.

Und wie nun die traurige Komödie des in Köln begonnenen und in Rom fortgesetzten Processes gegen Reuchlin sich abspielte, war mit einem Male eine öffentliche Meinung in Deutschland vorhanden und wirksam, welche für die neue "wahre Theologie" eintrat. In den Briefen berühmter Männer (1514. 1519) wurde über die Schaar der Reuchlinisten Heerschau gehalten, und in den „Briefen der dunklen Ehrenmänner" (1515-1517) wurde die Obskurantenpartei zum Objekt einer populären satyrischen Darstellung gemacht, wie sie im Geiste dieses deutschen 16. Jahrhunderts lag, das nun muthig und gesund allem Abgestorbenen den Krieg machte. Hier ist mit derben Zügen und in manchen unfläthigen Situationen der deutsche theologische Don Quixote des 16. Jahrhunderts hingestellt worden: der

7) „Est unus deus et una dea. Sed sunt multa uti numina ita et nomina: Jupiter, Sol, Apollo, Moses, Christus, Luna, Ceres, Proserpina, Tellus, Maria. Sed haec cave enunties. Sunt enim occultanda silentio tanquam Eleusinarum dearum mysteria. Utendum est fabulis atque enigmatum integumentis in re sacra. Tu Jove, hoc est optimo maximo deo propitio, contemne tacitus deos minutos. Quum Jovem nomino, Christum intelligo et verum Deum.“ 
grobsinnliche, bornirte, faule, unwissende, tölpische Pfaffe, welcher der neuen Zeit vergeblich sich entgegenstemmt. Hier wird der Ablass vor Luther bekämpft. Und hier wird mit spärlichen Worten, doch darum nicht minder wirkungsvoll auf die neue wahre Theologie hingewiesen, deren Vorbilder Erasmus und Reuchlin sind. Diese Theologie geht auf die Quellen in der Ursprache zurück, sio macht die Kirchenväter wieder zugänglich, und sie vereinfacht die gothisch verschnörkelte Theologie und Kirchendisciplin zu dem Evangelium: wer recht handelt, wird selig.

In Zusammenhang mit diesem religiös universellen Theismus entwickelte sich nun aber in den deutschredenden Ländern ein neues religiöses Lebensideal.

In Italien war das christlich asketische Lebensideal zurückgetreten hinter der natürlich aus ihren Anlagen entfalteten, in sich vollendeten Persönlichkeit. Hier entwickelte sich im 15. Jahrhundert der uomo universale. In der Selbstbiographie Leon Battista Alberti's, in den grossen Umrissen der. Person des Lionardo da Vinci ist er erkennbar. „Für die Thätigkeit," sagt Leon Battista Alberti, ,ist der Mensch geschaffen, das ist sein Zweck; Nutzen zu bringen, seine Bestimmung." Diese Menschen ruhen ganz auf sich selbst und streben ihrem natürlichen $W^{\top}$ esen die freieste Vollendung $\mathrm{zu}$ geben ${ }^{8}$ ). - Einem verwandten Ideal giebt Rabelais in der Schilderung seiner idealen klösterlichen Genossenscbaft im Gargantua Ausdruck. „En leur reigle nostoit que ceste clause: Fay ce que vouldras. Parce que gens liberes, bien nayz, bien instruictz, conversans en compeignies honnestes, ont par nature ung instinct et aguillon qui tousjours les poulse à faictz rertucux, et retire de vice: lequel ilz nommoyent honneur ${ }^{9}$ )." - Und ebenso hat in England Thomas Morus in seinem gesellschaftlichen Idealbilde, der Utopia (1516), die religiösen Hauptsïtze, Unsterblichkeit und Gottesglauben, auf die Vernunft gegründet und als die Bedingungen menschlichen Glückes und menschlichen Zusammenlebens aufgefasst: die Gesetze der Natur sind auch die Gesetze

Für den năheren Beweis tnuss auf Jacrib Hurckharlt's Kultur der henaissance in Italien, besonders Abschnitt 11 in $14143 \mathrm{f}$. Terwiesen werden.

T) Gargantua 1 c. 37. 
dessen, der den Christenglauben schenkt; und wahre Religiosität liegt nicht in religiösen Observanzen, sondern in dei ehrenhaften Erledigung der täglichen Pflichten.

Auch in Deutschland tritt, wo der Humanismus einwirkt, in das bedeutende Leben kraftvoller Personen nun ein gesteigertes Bewusstsein ihres Selbst, wie es sich überall an der Verehrung der moralischen Grösse der Alten entwickelt hat. Schon in der Mitte des fünfzehnten Jahrhunderts fand sich der damals "gelehrteste und beredteste unter den Deutschen", wie ihn sein Meister Aeneas Sylvius nannte, Gregor von Heimburg, in seinem einflussreichen Wirken mit den Alten eben durch das in diesen waltende Gefühl und Ideal des Lebens verbunden. Sie bestärkten ihn in der unbefangenen Freude am Wirken in der Welt. Dem Dominium der römischen Kirche setzte er die Selbständigkeit des Menschen im Glauben gegenüber. "Nam compulsis et invitis nihil vel modicum prodest fides et quaecunque exhibitio fidei. Constat enim coacta.servitia Deo non placere ${ }^{10}$ )." Ihn belebt die Denkart der männlichen römischen Autoren. Diese tritt zur selben Zeit in einer Vertheidigungsschrift des Sigismund von Oesterreich gegen Pius II. hervor: er beruft sich auf.das "jus naturae quod nemo nobis prohibere potest, nec a nobis auferre, quia natura nobis instinxit et nobiscum natum est" ${ }^{11}$ ).

Als solche Persönlichkeiten standen dann vor den Zeitgenossen im Reformationszeitalter der Ritter Hutten und der städtische Patricier Willibald Pirkheimer. Hutten zumal ist der erste Deutsche, der seine Persönlichkeit mit antikem Selbstgefühl in jeder Wendung seiner Existenz dem Publikum beinahe aufdrängte. Pirkheimer zeigt sich in Dürer's Portrait als stattlich und gross gebauter Mann, vom Gefühl seiner Würde erfüllt,.mit ausdrucksvollem Antlitz. Er hatte von den Alten wie Aeneas Silvius und Gregor von Heimburg vor Allem Freude am Leben und Wirken, gesundes Gefühl seiner Person gelernt. Das italienische Ideal des universalen Menschen verkörpert sich hier in einer echt deutschen

10) Goldasti Monarchia I 558.

11) Goldast II 1581. Hier auch kraftvoll der nationale Gesichtspunkt. „Nostrum est, patriam nostram tutare alacriter." 
Natur und einem reichsstädtisch-bürgerlichen Leben. Auch bei ihm finden wir als Kern aller die Person zusammenhaltenden Ueberzeugungen die römische Stoa und deren in sich gefasstes männliches Lebensgefühl. So schreibt or an seine Schwester Charitas. „Solche der wahrhaften Tugend Güter sind viel herrlicher als alle vergänglichen Titel und Ehren, welche nicht im Marmelstein oder Erz, sondern in der owigen Glorie Monumenten eingeschrieben sind und allon Reichtum weit übertreffen, auch sollen dann alle Ehren glänzen und allen Adel übertreffen und einthun, endlich auch fester, wahrhafter und beständiger sind und bleiben, denn alle äusserliche und zerfliessende Dinge. Sintemal sie nicht allein die Menschen, so in dem Meer dieser Welt hin und wider schweben, wallen und umgetrieben werden, ganz sicher und unverzagt in den Port der höchsten Selig- und Unsterblichkeit leiten und führen können, sondern auch die Kraft haben, alle menschlischen Widerwärtigkeiten, Jammer und Elend heilsamlich zu kurieren. Derowegen die Philosophi Stoici vernünftig und weisslich fürgegeben haben, dass wir leben, solches sei von der Natur; dass wir aber ernst und recht leben, solches sei der Philosophiae zuzuschreiben. Zwar nicht Wunder, dieweil den Menschen von Gott nichts Höheres noch Herrlicheres gegeben ist als ebendieselbe." Lnd ein anderes Mal: „So sollen wir nun init der Philosophie versehen, bewährt und bewappnet sein und Fleiss hinwenden, dass wir alles Ungemach beherzet und grossmüthig ausstehen." Ebenso hebt er im Lob des Podagra hervor: „unerschrocken und nicht im Geringsten furchtsam sein, das Niedrige verachten und nur nach dem Erhabenen und Grossen streben, um der Tugend willen auch das Rauhe und Schwierige ertragen, standhaft bei dem gefassten Vorsatz bleiben ". In der Ermahnung des Kindleins Jesu an die Jünger sagt er:

\section{- Gang nicht müssig, arbeit hier auf Erden, So magstu reich und selig werden.*}

Lnd indem nun bei uns durchgehends das Denken und Dichten in den festen deutschen Ordnungen und in christlicher Ehrenfestigkeit verbleibt, giebt der Persönlichkeit dies antike Bewusstsein ihrer natürlichen Kraft eine neue Form. Das vom Gefühl für das Gemein- 
wesen erfüllte Wirken, zumal in den Städten, findet sich selbst in den Alten wieder. So unbefangen, in naivem Einverständniss, hatten gleichsam zusammen und befreundet mit den Athenern und Römern die Florentiner der grossen älteren Zeit gelebt; nun wiederholte sich das bei den Bürgern von Nürnberg und von den anderen Reichsstädten, bei den Räthen der Reichsregierung, bei ritterlichen Herren und populär wirkenden Schriftstellern. So spricht sich gerade vor Luther's Auftreten im Gegensatz gegen die kirchliche Disciplin und Askese das ruhige und feste Zutrauen des tüchtig wirkenden Mannes auf sich selbst und sein natürliches Verhältniss zu Gott in der ganzen Literatur aus.

Sebastian Brant ist der hervorragendste literarische Vertreter des aufkommenden Bürgerthums in der Generation vor Luther. In seinem Narrenschiff, das 1494 zuerst gedruckt wurde, sagt er:
"Schau den Duckmäuser!...
Wir wollen ja doch auch erwerben,
Dass uns Gott lässt in Gnaden sterben,
Wie er, obgleich er Tag und Nacht
Liegt auf den Knien, betet und wacht;
Er will nur fasten und Zellen bauen,
Wagt weder Gott noch der Welt zu trauen!
Gott hat uns darum nicht geschaffen,
Dass wir Mönche werden oder Pfaffen,
Und zumal, dass wir uns sollten entschlagen
Der Welt!...

Es ist Gottes Wille und Meinung nicht,

Dass man der Welt so thue Verzicht

Und auf sich ganz allein hab Acht."

Hutten in seiner Satyre auf die Zeiten Julius II., yor Luther's Auftreten noch geschrieben, bekämpft den "Wahn, ein Bandit wie Julius besitze die Schlüssel des Himmels“. „Wie? Der menschliche Geist, ein Funke des göttlichen Lichtes, von Gott selber ein Theil, lässt so durch Wahn sich verblenden?"

„Muth, Landsleute, gefasst! Ermannen wir uns zu dem Glauben,

Dass wir das göttliche Reich durch redliches Leben erwerben;

Dass nur eigenes Thun, und nimmer der heiligste Vater

Heilig uns macht $\left.{ }^{12}\right) .{ }^{*}$

12) In tempora Julii satyra. Schriften III 269 f. Strauss, Hutten (ges. Schr. VII 69). 
Im Gegensatz zu den alten Todtentanzbildern, die den Menschen unter dem Druck der dunklen Mächte zeigen, hat Dürer auf der Höhe seines Lebens, 1513, in seinem Ritter, Tod und Teufel die sieghafte Macht des Menschen wie kein anderer Maler dieser Zeit zum Ausdruck gebracht. Daneben hat er Erasmische humanistische weise Friedseligkeit in seinem heiligen Hieronymus hingestellt. Er erzählt von seinem Vater in seinem Tagebuch. Derselbe „wandte grossen Fleiss auf seine Kinder, sie zur Ehre Gottes zu erziehen; denn sein höchster Wunsch war, dass er seine Kinder in Zucht wohl aufbrächte, damit sie Gott und den Menschen angenehm würden. Darum war seine tägliche Rede zu uns, dass wir Gott lieb haben sollten und treulich handeln gegen unseren Nächsten ${ }^{13}$ )". Wie drückt sich dann sein grosses Gemüth, das in tüchtigem Wirken einfach dem in der Bibel enthaltenen höheren Zusammenhang der Dinge hingegeben ist, in der Stelle seines Tagebuches aus, die über die falsche Nachricht von Luther's Gefangennehmung 1521 niedergeschrieben ist! Er hofft nun, Erasmus werde der Führer sein. „Höre, Du Ritter Christi! reite hervor neben dem Herrn Jesus, beschütze die Wahrheit, erlange die Märtyrerkrone! Du bist doch ohnedies schon ein altes Männchen. Ich habe ja von Dir gehört, dass Du Dir selbst nur noch zwei Jahre zugegeben habest, die Du noch taugest, etwas zu thun."

Pamphilus Gengenbach in seinem Gedicht „Der alt Eidgenoss“ von 1514 zeigt den Schweizern seiner Zeit im Bilde der früheren Generation sein Ideal.

\footnotetext{
"waren from biderb Leut,

Viel Berg und Thal hand sie gereut,

Dess thäten sie sich nähren.

Kein Untreu, Hoffahrt war in ihnen

Und dienten Gott dem Herrn.

Brüderliche Treu war unter ihn",

- In ganzer Einfalt zogen's hin

Und batten Gott im Herzen."
}

Ein Gedicht gegen die „Todtenfresser ${ }^{\text {}}$ d: h. die Geistlichen, die von den Todtenmessen leben, ist wohl geschrieben bald nach

25) Dürer's Tagelucb bei Thausing S. 73.

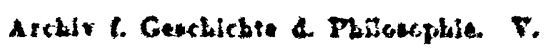


Luther's sermo de poenitentia. Während die Geistlichkeit vom Papst bis zur Klostermagd sich des guten Lebens aus den Todtenmessen erfreuen, klagen die Seelen der Todten. Da sagt unter Anderen der Bauer:

\footnotetext{
Von minen Eltern hab ich ghört, wer sich siner handarbeit nert, der sei selig und werd ihm wol.
}

Diese weltfreudige, gerade gewachsene Frömmigkeit fand sich naturgemäss von Luther's Kampf gegen Rom hingerissen. Aber wie zumal im Streit mit Erasmus die Sünden- und Rechtfertigungslehre sich geltend machte, fand eine Secession statt. Die Einen wurden von Luther's mächtiger Person nachgezogen, die anderen fanden sich vorwiegend abgestossen. Pirkheimer's Schwester Charitas findet in ihren Denkwürdigkeiten eben das unerträglich, dass „der Mensch keinen freien Willen hat", "dass Gott ohne Zuthun des Menschen denselben selig oder unselig haben will $\left.{ }^{14}\right)^{\text {", }}$, und Pirkheimer selbst war mit ihr hierin einig ${ }^{15}$ ). Besonders klar drückt sich Theobald Thamer aus. „Es ist etwas wahr, nicht deshalb, weil es in der Bibel steht, sondern weil es an sich wahr ist, steht es in der Bibel. Diese kann mit der Wahrheit, wie sie in dem Gewissen und in den Kreaturen sich offenbart, nicht im Widerspruch stehen, sondern sie setzt dieselbe voraus ${ }^{16}$ ).“

So war noch ehe Luther auftrat, von dem Humanismus ein religiös universalistischer Theismus verbreitet worden. Jeder, der damals, befreit von der mittelalterlichen Theologie-Metaphysik, seinen Cicero oder Seneca las, ward in diesem Theismus befestigt. Diesem Standpunkte entsprach ein Lebensideal von Entfaltung der natürlichen Anlagen und von lebensfrohem Wirken in der Welt. In derselben Richtung wirkte der Uebergang aus dem Stadium der

14) Denkwürdigkeiten der Charitas Pirkheimer, her. v. Höfler. Vorw. XXXVI, aus Lochner, gesch. Studien S. 86.

15) Brief an Kilian Leib, ebds. S. XXXVIII, vergl. Döllinger's Reformation I 533.

16) In Neanders merkwürdigem Buch über Thamer (1842) S. 25. Vergl. die Stellen über die Autonomie des Gewissens auch der Schrift gegenüber, S. 24: „das Gewissen die geoffenbarte Gottheit selber", S. 28: dasselbe ist der innere Christus oder das lebendige Wort. 
kriegerischen Feudalität in das veränderter Waffen und veränderter Kriegführung, der Unterwerfung eines übermüthigen Adels durch die Fürsten und der Entwicklung von Industrie und Handel in den Städten: eine Zunahme der wirksamen geistigen Energie in der europäischen $W^{r}$ elt fand statt. Zumal in Deutschland fand man diesen universalistischén Theismus und dies aktive Lebensideal in Einklang mit der echten Theologie, der Philosophie Christi, wie man sie aus der philologisch kritischen Behandlung der Quellen des Christenthums abzuleiten hofite. Diese gesunde, ehrenfeste, rechtschaffene, weltfreudige Frömmigkeit, wclche in der männlichen Einheit wissenschaftlichen Denkens und frommen Glaubens lebte, unterwarf bei uns die verfallenden Ordnungen des Mittelalters, insbesondere aber die heteronome Regulirung des sittlich religiösen Processes durch die Kirche, einer von gesundem Verstand getragenen Kritik. Den religiös sittlichen Process im Menschen zu simplificiren und dem kirchlichen Apparat gegenüber selbständig zu gestalten: das war das Bedürfniss, das bei uns überall sich regte. Und wie später unter dem Schutze von Friedrich, Catharina und Joseph, der französischen Aristokratie jene Philosophie zur Herrschaft in der Literatur gelangte, welche dann von der französischen Revolution ab die Erschütterung der Throne zur Folge hatte, genau so haben die eben dargestellten Ideen sich während des 15. Jahrhunderts und am Beginn des 16. der Ermuthigung oder doch der stillschweigenden Toleranz der Päpste, Cardinäle und Bischöfe zú erfreuen gehabt, welche dann ron diesen Ideen bedroht wurden.

\section{Luther kam.}

Es giebt in der Menschheit nicht nur eine Continuität der fortschreitenden Wissenschaft, sondern auch eine solche der religiös moralischen Entwicklung. Wie sich ein Mensch fortschreitend im Zusammenhang seiner Lebenserfahrungen auslebt, so auch das Yenschengeschlecht selber. Und zwar sind die grossen Veründerungen im sittlichen Leben stets mit denen des religiösen verbunden. Die Geschichte spricht nirgend bisher für das Ideal der religionslosen Moral. Neue aktive Willenskräfte sind, soweit wir sehen, immer in Verbindung mit den Ideen über das Unsichtbare entstanden. Es entspringt nun aber das fruchtbare Neue auf diesem Gebiet immer in 
geschichtlichen Zusammenhang selber, auf der Grundlage der Religiosität einer ablaufenden Epoche, wie ein Lebenszustand aus einem früheren hervorgeht. Denn nur indem dem echt religiösen Menschen eben aus dem innigsten, tiefsten religiös sittlichen Erfahren im vorhandenen Verbande auf Grund der veränderten Bewusstseinslage ein Ungenüge entsteht, ist Anstoss und Richtung für das Neue gegeben. So ist es auch in Luther gewesen. Er wollte den Katholicismus reformiren: er wollte das Evangelium erneuern. Wie wir heute das älteste Christenthum kennen, geht sein und seiner Genossen moralischer Begriff des Menschen einen entscheidenden Schritt weiter auf der Bahn der religiös sittlichen Entwicklung auch über das älteste Christenthum hinaus. Aus dem traditionell bedingten und belasteten Bestand seiner Ideen dies Neue auszusondern und auszusprechen, ist die Aufgabe.

Luther hat in sich alle Motive der Opposition gesammelt. Eine ausserordentliche Gabe trat bei ihm hervor, die Bedürfnisse der Zeit nachzufühlen und ihre lebendigen Gedanken zu vereinigen. Zugleich besass er doch in seinem religiösen Genie eine einsame und einseitige Kraft, welche die Zeitgenossen wie mit einer höheren ihnen fremden Gewalt ein Stück Weges oder ganz nach sich zog. $\mathrm{Er}$ war zum Handeln und zum Herrschen geboren. In seiner Person lag etwas Selbstherrliches, Souveränes. Seine-Invektiven gegen den Herzog Georg als den Apostel des Teufels, gegen den König von England als den Hanswurst, dessen Schrift gegen den Protestañtismus er mit dem Schimpfen einer zornigen öffentlichen Dirne verglich, der wilde Humor in der Schrift über die Bulle vom Abendfressen des Allerheiligsten Herrn, des Papstes, sind der Ausdruck des Machtgefühls eines furchtlosen Menschen. Er tröstet einmal Melanchthon in dessen Anfechtungen damit: was denn der Teufel mehr thun könne, als ihn erwürgen? Schon 1516 finden wir den Augustinermönch umdrängt von Geschäften: zwei Schreiber könnte er allein für seine Briefe gebrauchen. Seine dämonischen Augen, die dem Legaten Cajetan schon an dem Jüngling so unheimlich waren, durchdrangen alle Wirklichkeiten dieser deutschen Welt. Und seine tapfere Energie, sein Verständniss der Wirklichkeit, seine Herrschaft über sie beruhte auf dem beständig ihm 
bewussten Zusammenhang mit dor unsichtbaren Welt. Mögen wir mit der Stoa oder Luther, mit Kant oder Carlyle fühlen: hier ist der einzige Fond heroischen Handelns, und Voltaire's ohne Zahl würden es nur zur Unterwerfung der Klugen unter die Herrschaft der rohen Kraft bringen. Ihm war eine einfache Seele gegeben, bei allem übersprudelnden schaffenden Vermögen und allem genialen Reichthum des Gemüthes. In seinem Glauben waltet das den Willensmenschen Eigene, das von Person zu Person geht. Aus dieser einfachen und doch so reichen Natur heraus vollbrachte er die Reduktion des kirchlichen Wustes, erfasste dio Ganzheit des Nenschen im Glauben, riss die Nation von Rom los und blieb dem grössten Theil derselben selbst dann noch verständlich und nahe, als die harte Einseitigkeit seiner Auffassung des religiös sittlichen Processes immer mehr sichtbar wurde. Er beherrschte die Menschen scincr Zeit, weil sie ihr potenzirtes Selbst in ihm zu crkennen glaubten. Als der Befreier der persönlichen Religiosität von dem römischen Priesterregiment in einem Kampf auf Leben und Tod hat er die Besten seiner Zeit an sich gezogen. Luther die Bulle verbrennend, dann in Worms, auf der Wartburg: das ist der Luther, den die Nation lieben wird, wenn die persönliche Ausprägung der Religiosität, die ihm hiezu den heroischen Willen gab, längst anderen Formen des Glaubens Platz gemacht haben wird. Neben ihm Zwingli auf der Kanzel des Züricher Münsters und auf dem Schlachtfeld von Kappeln.

Es soll also das ausgesprochen werden, was Luther rückwärts mit der deutschen Mystik, vorwärts mit unserem transscendentalen Idealismus verbindet und rodurch er zugleich den Zeitgenossen der Erneuerer der Gesellschaft auf den tiefsten religiös moralischen Grundlagen war. In den drei grossen Schriften von 1520 ist es enthalten. Von der Freiheit eines Christenmenschen; Sermon von guten Werkev; An den christlichen Adel deutscher Nation von des christlichen Standes Besserung. Doch muss es- aus diesen Werken ausgesondert werden; denn es ist in ihnen mit Bestandtheilen härterer und gröberer Art, dem überlieferten Dogma und der Sünden- und Rechtfertigungslehre vermischt. Von diesen Bestandtheilen muss zunächst die Rede scin. 
Es ist eines der Gesetze der Religionsgeschichte, dass der menschlische Glaube in der historischen Continuität und in dem roligiösen Gemeinschaftsverbande allein kräftiges Leben und Fortentwicklung hat. Luther's kirchenbildende Macht lag eben darin, dass seine Reform diesem Gesetz entsprach. Wenn das erste Edikt des Justinianischen Codex, durch welches der Ertrag der dogmenbildenden Concilien bis zu dem von Nicäa festgelegt wurde, noch zu Luther's Zeit die Basis des öffentlichen Rechtes bildete, so hat Luther auf diesem Rechtsboden gestanden, und auch der innerlich freiere Zwingli hat in dem Marburger Gespräch sich auf diesen Boden gestellt. Dàs Rückenmark der mittelalterlichen Kirche war der Augustinismus. Die Umformung desselben, wie sie der Augustinermönch aus dem Bedürfniss von Innerlichkeit, Selbständigkeit und Sicherheit des Glaubens vollzog, änderte Form und Begründung der in Nicäa abgeschlossenen Dogmen vermittelst der Aenderung in der. Lehre von der Aneignung des Heils. Die Justifikation, welche der mittelalterliche Mensch an sich erfuhr, war ein objektiver aus der transscendenten Welt durch die Menschwerdung in den Kanälen der kirchlichen Institute, Priesterweihe, Sakramente, Beichte und Werke auf die Gläubigen herabfliessender Strom von Kräften, ein übersinnlich regimentaler Vorgang. Die Rechtfertigung durch den Glauben, die Luther erlebte, war die persönliche Erfahrung des in der Continuität der christlichen Gemeinschaft stehenden Gläubigen, welcher die Zuversicht zu der Gnade Gottes aus der durch die persönliche Gnadenwahl herbeigeführten Aneignung der Leistung Christi im persönlichen Glaubensvorgang erfuhr. Musste hiernach eine Veränderung in der Bewusstseinsstellung zum Dogma und in der Begründung des Glaubens an dasselbe eintreten, so berührte dieșelbe doch die Materie des altchristlichen Dogma nicht.

Der Glaubensgehalt Luther's, sofern er sich in den Begriffen von Sünde und Gnade, Rechtfertigung und Versöhnung durch den Opfertod Christi, Sakrament und kirchlichem Zusammenhang der Gläubigen auseinanderlegt, ist neuerdings seit Ritschl's bedeutender Darstellung schärfer als früher dargelegt worden, und so darf hier auf diese Darstellungen, besonders auf die meisterhafte von 
Harnack verwiesen werden ${ }^{17}$ ). Es unterliegt koinem Zweifel, dass in Luther wie in Zwingli die Energie des moralischen Urtheils, das sichere Bewusstsein vom Zusammenhang des Menschen durch sein Gewissen mit einem höchsten Richter, die fröhliche Zuversicht, vor ihm gerechtfertigt, als sein Werkzeug in der Wolt wirken zu dürfen, einen tieferen Ausdruck als vorher jemals gefunden haben. Gerade dieser mit der grossen Tradition der Kirche einige Glaubensinhalt gab den Reformatoren die heroische Kraft, Apparat und Disciplin der Curio abzuschütteln und kirchenbildend' zu wirken. Aber zugleich muss es doch dabei bleiben: dieser Zusammenhang religiŏser Begriffe ist nicht der Ausgang des Dogma das „Ende des alten dogmatischen Christenthums" (wenn man nur unter diesem nicht ein in wissenschaftlicher Beweisführung verknüpftes System versteht), sondern hat dieses überall zu seiner nothwendigen Voraussetzung. Er steht und fällt selbst mit dem Dogma. Ja sogar das mönchische, franziskanische religiöse Ideal muss als die Voraussetzung für die Lehre von der Sünde und von dem Unvermögen zum Guten angesehen werden ${ }^{18}$ ). In dem Maasse, in welchem die Erbsündenlehre von dieser dualistisch mutivirten Enterlage losgelöst wurde, musste sie $\mathrm{zu}$ einer ganz unhaltbaren Darstellung der Erfahrungen über die Menschennatur greifen. Dann Luther's Lehre von Christus und der Rechtfertigung durch ihn macht allerdings Christi ,Amt und Werk, so er auf

i) Ritschl, christliche Lehre von der Rechtfertigung $11126 \mathrm{ff}$. Herrmann, Verkehr des Christen mit Gott, 1886. Harnack, Dogmengeschichte $111700 \mathrm{ff}$. lliemit sind aber dann die eine andere Auffassung vertretenden Darstcllungen ron Lommatzsch (Luther's Lebre rom ethisch religiösen Standpunkte aus 1879) und höstlin zu rergleichen.

19 Anders Ilarnack, a. a. 0.713. Doch nach Conf. August. Art. 2 bestebt das peccatum originale keineswegs einfach in dem Unvernögen, Gott zu vertrauen, sondern gleichwerthig in dem: quod omnes homines nascantur sine metu Ici und cum concupiscentia. Auch ist nicht der Zusammenhang mit der Genchlechtslust aufgehoben, sondern die Apologie bebt ausdrücklich aus der deutxcben Confession hervor das: in Sünden empfangen und geboren, das ist ron Intterleib an voll biser lust*, überbaupt die Bedeutung der concupiscentia. lliermit ist ja droch auch schliesslich Lnther's Ansicht von der Ehe in Uebereinstimsnug. Das wahre Letrensideal hat im Gegensatz hierzu die Moglichkejt einer ethischen Gestaliug des Trieblebens zur Voraussetzung. 
sich genommen hat", zum Kern des Dogma gegenüber den meta-. physischon Wesensbestimmungen. Aber eben hierdurch wird der Opferbegriff, dieser dem , sittlichen Gefühl härteste Theil des ganzen Jogma, noch entschiedener in den Vordergrund gestellt. Die Einschränkung der zeitlichen und ewigen Seligkeit auf die durch den Opfertod vermittelst des Glaubens Gerechtfertigten und Versöhnten, ein Dogma, das, wohl machtvoller und verhängnissvoller in das Fühlen der Menschen eingreift, als jedes metaphysisch geartete, wird einseitiger als je vorher bei Luther festgehalten. Und die nothwendige dogmatisch-metaphysische Voraussetzung dieser ganzen Lehre liegt ja doch in der aus dem sündigen Zusammenhang der ganzen Menschheit losgelösten Natur Christi. Endlich bewahrte Luther's Abendmahlslehre die ganze metaphysische Dogmatik der Gottmenschheit in sich. Alle diese dogmatischen Voraussetzungen sind allerdings in den Dienst einer gemüthsmächtigen Zuversicht des Glaubens gestellt; sie werden hierdurch Theile einer einzigen lebendigen Erfahrung; sie werden der Vernunftreflexion entzogen. Aber sie bestehen fort; die Rechtfertigungslehre selbst existirt nur so lange, als diese ihre dogmatischen Voraussetzungen gelten.

Nun aber wenden wir uns zu dem Neuen in Luther und Zwingli, das über deren Paulinismus und Augustinismus hinausreicht: das innere Fortschreiten der Fassung und Begründung unserer der höheren Ueberzeugungen suchen wir zu ergreifen.

Das griechische Christenthum war in der Bildlichkeit anschaulichen. Denkens verblieben. Sein intelligibler, transscendenter Kosmos war das Gegenbild des anschaulich gegebenen Kosmos. Seine Transscendenz überschritt nirgend das anschauliche Denken. Es lebte in dem übersinnlichen Schauspiel der Trinität, der ewigen Zeugung und einer Welt von göttlichen Kräften. Das römische Christenthum war regimental.' Der römische Geist konnte den religiösen Process nur als an ein neues geistliches Imperium gebunden denken. Das höhere Leben floss von Gott her nur in der von diesem Gottesstaat geregelten Ordnung und Disciplin auf die Christen. nieder. Die Fides implicita war der Gehorsam von Unterthanen. Erst bei den nordischen Völkern tritt der religiöse Process in die 
Unsichtbarkeit. Er erfasst seine völlige Verschiedenheit von den anschaulichen Denkvorgängen, wio sie in den Formeln und Beweisen des griechischen Dogma wirksam sind, und or löst sich von dem äusseren Apparat von Mitteln, Disciplin und Werken in cinem Gehorsam heischenden geistlichen Imperium los, wie dieser von dem römischen Herrschergeiste geschaffen worden war. Indem Luther dies vollbringt, schliesst in ihm vollends die tiefste Bewegung des Mittelalters, das franziskanische Christenthum und die Mystik ab, und zugleich beginnt in ihm der moderne Idealismus. In der franziskanischen und mystischen Bewegung hatte sich die gänzliche Loslösung des religiösen Vorgangs von allem egoistischen Interesse des Nenschen vollzogen. Es musste einmal diese tief wahre, obwohl nur die Eine Seite des religiös sittlichen Processes enthaltende Gemüthsverfassung bis in ihre letzten Consequenzen entwickelt werden. Iuther, eines Bergmanns Solnn, in nordischen Bergen, ein Mönch in Jebeln, Schnee und Unbildlichkeit der Natur, ohne einen Schimmer von Kunst in seiner Seele, auch ohne eil stärkeres Bcdürfniss nach Wissenschaft, nichts als Unsichtbarkeit alles Höheren um sich, Unbildlichkeit höherer Tiräfte und Kraftverhältnisse: Er erst hat den religiösen Process ganz losgelöst von der Bildlichkeit des dogmatischen Denkens und der regimentalen Aeusserlichkeit der Kirche.

Leben ist ihm das Erste. Aus dem Leben, aus den in ihm gegebenen sittlich religiösen Erfahrungen stammt ihm alles Wissen über unser Verhälniss zum Unsichtbaren und bleibt daran gebunden. End so tritt das intellektuelle Band des Kosmos, das die Vernunftwesen an die Weltvernunft bindet, zurück hinter den moralischen Zusammenhang.

Cnd blieb auch Luther ablehnend gegenüber dem religiös universalistischen Theismus, unter der Deckung seiner nominalistischen Voraussetzungen: um so entschiedener ergriff der Voran-chreitende das Lebensideal der Zeit: überall umgab es ihn: er erfasste es im höchsten Sinne: der innere Glaubensvorgang hat seinen Ausdruck und scine Wirkungssphäre in der Gestaltung der ganzen äusseren Ordnung der Gesellschaft. Wie schrumpfte ihm später dies Ideal ein! 
Von dieser Position aus entwickelt der im Oktober 1520 deutsch und lateinisch veröffentlichte. Traktat von der Freiheit einés Christenmenschen die Summe eines christlichen Lebens, d. h. den religiösen' Process, wie er Luther's Christenthum damals ausmacht. Der Mensch ist in dem religiös moralischen Process :als dem Mittelpunkt seines Seelenlebens frei. Mit stoischer Energie erklärt Luther von der Gefangenschaft des Leibes, der Krankheit and dem Schmerz: keines „dieser Dinge reiche bis an die Seele, sie zu befreien oder zu fangen“. Und mit dem Idealismus eines Carlyle oder Fichte bezeichnet er heilige Kleider, heilige Orte, Umgang rnit heiligen Dingen als gänzlich gleichgültig ${ }^{19}$ ). Der religiöse Process ist in seinem Kern ein Unsichtbares, dem. Verstande ganz Unzugängliches: der Glaube ${ }^{20}$ ). Die Gegenwart des göttlichen Wortes in der gläubigen Seele ist eine unzerlegbare Erfahrung, deren Kennzeichen die Zuversicht auf Gott ist. "Allein das Wort und Glaube regieren in der Seele. Wie das Wort ist, so wird auch die.Seele von ihm: gleich als das Eisen wird glutroth, wie das Feuer, aus der Vereinigung mit dem Feuer ${ }^{21}$ ). " Dieser wirksamste, sprachgewaltigste Schriftsteller unserer Nation trug, nun aber zugleich einen Dichter in sich. Mit einer einzigen Kraft der Innigkeit und der herzlichen Poesie kleidet er seine christliche Erfahrung in Symbole. „Ist nun das nicht eine fröhliche Wirthschaft, da der reiche, edle, fromme Bräutigam Christus die arme verachtete böse Seele zur Ehe nimmt ${ }^{22}$ )?" „Wer mag nun ausdenken die Ehre und Höhe eines Christenmenschen? Durch sein Königreich ist er aller Dinge mächtig, durch sein Priesterthum ist er Gottes mächtig ${ }^{23}$ )." In diesem Vorgang ist zunächst jenes harte Verhältniss der Erbsünde zu der Rechtfertigung vor Gott durch den Glauben vermittelst

19) Freibeit $\S 3-4$.

20) Die Funktion des Geistes ist: „unbegreif liche, ewige, unsichtbare Dinge zu erfassen." Magnifikat 1521. - Im Verhältniss zum Glauben kann nach dem „Sermon" auch die Liebe als das Erste gefasst werden. „Denn ich möchte Gott nicht trauen, wenn ich nicht gedächte, er wolle mir günstig und hold sein, dadurch ich ihm wieder hold und beweget werde, ihm herzlich zu trauen."

21) § 10 .

22) $\S 12$.

23) $\S 16$. 
des Blutes Christi enthalten, welches Luther in Paulus und dem Augustinismus um sich vorfand und seinem grossen Grundgedanken von der Selbstherrlichkeit der gläubigen Person unterordnete. Es ist aber in ihm zugleich auch dor tiefere und ursprünglichere Begriff einer Formirung der Seole nach Gott enthalten, der aus den Evangelien und der Mystik stammt ${ }^{24}$ ). Hieraus ergiebt sich das Verbältniss von Glaube und Werk. „Wie die Bäume müssen eher sein denn die Früchte, und die Früchte machen nicht die Bäume weder gut noch böse, sondern die Büumo machen die Früchte, also muss der Mensch in der Person zuror fromm oder böse sein, ehe er gute oder böse Werke thut ${ }^{\text {*3 }) ~ " ~ „ A l s o ~ f l i e s s e t ~ a u s ~ d e m ~ G l a u b e n ~}$ die Liebe und Lust zu Gott, und aus der Liebe ein freies, williges, fröhliches Leben, dem Nächsten zu dienen umsonst ${ }^{26}$ )."

Die vächste Consequenz dieser Lehre von dem ganz unsichtbaren und innerlichen Vorgang des Glaubens ist die königliche Freiheit des Christenmenschen und das allgemeine Priesterthum. Diese Freiheit ist nicht nur die äussere von der kirchlichen Disciplin, sondern auch die innere ron der ganzen Macht der Welt: übereinstimmend mit dem stoischen Begriff von der Freiheit. „Ein Christenmensch wird durch den Glauben so hoch erhaben über alle Dinge, dass er derselben Herr wird geistlich, denn es kann ihm kein Ding schaden zur Seligkeit. Ja es muss ihm alles unterthan sein und helfen zur Seligkeit." Die Freiheit des, innerlichen Menschen " und seine Herrschaft über alle Dinge besteht darin, dass jedes Ding ihm zum Gut wird und er doch keines bedarf ${ }^{27}$ ). Die Christen sind sonach alle durch ihren Glauben independent. Das Priesterthum ist allgemein. Das geistliche Amt ist nur ein Amt, ein Dienst, eine „Schaffnerei ${ }^{*}$, und die ,weltliche, äusserliche, prächtige, furchtbare Herrschaft ${ }^{\alpha}$, welche daraus geworden ist, muss verworfen werden $"$ ).

24) \$ 6 und in lateinischen Text, Opp. 1235 . Vergl. in lyezug auf die Verneinung dey einzelpen zeitlichen Vorgangs, welche an die Fassung Kant's erinnert, die anlere Stelle, Opp. 11327.

23) \$ 23.

26) $\$ 27$.

27) $\$ 1.5$.

in 17 . 
Der Sermon von den guten Werken wird von Luther selbst als zusammengehörig mit dem. von der Freiheit angesehen ${ }^{29}$ ). Das Verhältniss des Glaubens zu den guten Werken wird in diesem Sermon als das der Gesundheit des ganzen Leibes zu dem Wirken der einzelnen Gliedmassen dargestellt. „Das Leben ruhet nimmer“. Die Menschennatur ist immer Aktion: so muss beständig aus dem Glauben das Werk hervorgehen ${ }^{30}$ ). Die Werke entspringen aber von selber aus dem Inhalt des Glaubens, da der Gläubige in diesem „Christum in sich bild et ( $\left.{ }^{31}\right)$. Das Werk des Glaubens allein reichet bis zu Gott ${ }^{32}$ ). Und hier tritt uns nun das gestaltende Princip der socialen Moral Luther's entgegen. Aus dem Glauben folgt als dessen Aeusserung, „das Werk Gottes wirken in der Welt“. Gott „will mit und durch uns sein Werk wirken " ${ }^{33}$ ). Und nun entwickelt Luther aus dem Reichthum seiner inneren Erfahrung, anschliessend an die zehn Gebote, das gestaltende Wirken des Gläubigen in der Welt. Luthers Macht über die Deutschen beruhte auf den lebendigen Kräften von Umgestaltung der vorhandenen Gesellschaft, welche aus seiner neuen Art das Christenthum aufzufassen erwachsen sind. In einer willensmächtigen, erfinderischen, tiefsinnigen Generation, welche unter neuen Bedingungen stand und diesen gemäss die abgelebten Ordnungen der Kritik des gesunden Verstandes unterwarf und die Verfassung des Reiches endlich ordnen wollte, stand er allen voran. Zumal seine furchtlose Stellung zu den herrschenden Gewalten gewann ihm mehr als irgend etwas alle Besseren. „Es ist leicht zu fechten wider das Unrecht, das Päpsten, Königen, Fürsten, Bischöfen und anderen grossen Hansen widerfährt. Hier will ein Jedermann der frömmste sein." „Wo aber einem armen und geringen Menschen etwas widerfähret, da findet das falsche Auge nicht viel Geniess, siehet aber wohl die Ungunst der Gewaltigen; darum lässt er den Armen wohl ungeholfen bleiben.“ "Siehe das wäre wohl viel guter Werke vorhanden. Denn das

29) Brief an den Freiherrn von Schwarzenberg 1522.

30) W. Erl. A. Bd. 20 S. 206. 207.

31) Ebds. S. 212.

32) Ebds. S. 213.

33) Ebds. S. 227. 
mehrere Theil der Gewaltigen, Reichen und Freunden thun Unrecht, und treiben Gewalt wider die Armen, Geringen und Widerparten; und je grösser, je ärger ${ }^{34}$ )."

Hier greift nun aber wie ein never Ring in einer Kette in den Zusammenhang die praktisch mächtigste Schrift Luther's ein. An den christlichen Adel deutscher Nation, von des christlichen Standes Besserung, 1520. Sie handelt von dem Träger der Umgestaltung der deutschen Gesellschaft und von den Hauptmassregeln für eine solche Umgestaltung. Der Träger eines sozialen Wirkens, wie es aus der vertieften religiösen Sittlichkeit sich ergiebt, ist in der politischen Organisation der Gesellschaft gegeben. Der „innere Mensch", die Unsichtbarkeit des religiösen Processes in ihm, seine Freiheit enthalten in sich keine Verhältnisse von Gewalt und Gehorsam in einem kirchlichen Ganzen: nur der politische Verband ermöglicht die Organisation des sozialen Wirkens. So wird dieser Verband zum Sitz alles Wirkens für das Werk Gottes in der Welt. Die Sphäre der Werke des Glaubens ist die weltliche Gesellschaft und deren Ordnung. Mit diesem Satz ist erst die völlige Auflossung jedes Gedankens von kirchlicher Werkthätigkeit erreicht. In ihm gelangt der harte Kampf Luther's gegen die „Officialbuben“, gegen "die heiligen Gleisner", gegen Pomp, Macht und Menge der guten Werke, gegen all die "heiligen Kleider" erst zum Abschluss. In ihm tritt einer der grössten organisatorischen Gedanken, die je ein Nensch hatte, in die Geschichte. Dass es doch Luther nicht gelang, ihn in seiner Reinheit durchzuführen! Der mittelalterlichen Lehre von den beiden Reichen, dem weltlichen "und geistlichen, tritt nun der reformatorische Satz gegenüber: „Christus hat nicht zwei noch zweierlei Art Körper, einen weltlich, den anderen geistlich. Ein Haupt ist er, und Einen Körper hat er ${ }^{(25}$ ). Die weltliche Gewalt ist ,gleich nit uns getauft ${ }^{4}$, d. h. sie wird ebenfalls, von christlichen Personen geübt, sie ist sonach ebenfalls ngeistlichen Standes". Da sie nun nach göttlicher Anordnung mit $Z$ wang ausgestattet ist, so erhält durch sie die christliche Gesellschaft des deutschen Volkes

a) Ebuls. S. $225 \mathrm{f}$.

23) An den Adel, in der. Niederlegung der crsten Papiermauer", an Aufaug. 
ihre Organisation. Diese umfasst alle'sozialen Thätigkeiten, „Schuster, Schmied, Bauer hat jeglicher seines Handwerks A mt und Werk, mit diesem soll jeder dem anderen nützlich und dienstlich sein, in Einer Gemeinde ist also vielerlei Werk gerichtet, Leib und Seele zu fördern: wie die Gliedmassen des Körpers alle eins dem anderen dienen ". ${ }^{36}$ ) Eben solches Amt und. Werk für das Ganze vollbringen nun auch die $\mathrm{zu}$ kirchlichen Leistungen Beauftragten, vom Bettelmönch bis zum Papst. Und die Staatsgewalt beherrscht gleichmässig alle Aemter und alles Wirken. "So soll man ihr Amt lassen freigehen, ungehindert, durch den ganzen Körper der Christenheit." Indem sie nun aber von den neuen Ideen erfüllt ist, welche doch mit der ganzen Veränderung des europäischen Geistes in Zusammenhang stehen, muss sie der Träger und das Organ von Reformen auf kirchlichem wie weltlichem Gebiete werden. Im Namen des neuen christlichen Geistes fordert Luther eine Umgestaltung der deutschen Gesellschaft in ihren weltlichen und kirchlichen Ordnungen. . Dies war die Zeit, in welcher die Worte dieses deutschesten Menschen bald in jeder deutschen Brust nachklangen, und Alles was die Nation vom Reiche und seinem Regiment ersehnte mit Luther's Reform im Einverständniss erschien. Papstgewalt, Cardinäle, geistliches Recht, Annaten, Kaufgelder für das Pallium werden von Luther verurtheilt; überhaupt die Abführung von so viel deutschem Geld nach Rom; wer aus Rom kommt, eine dotirte Stellung sich übertragen zu lassen, sollte ins Wasser geworfen werden; keine Bestätigung eines geistlichen Amtes darf aus Rom eingeholt werden; der Papst soll nur in Glaubenssachen Aufsicht über die Bischöfe führen; überall müsste die schärfste Controle der Finanzgewalt der Kurie stattfinden. Im Kloster zu bleiben oder es zu verlassen, sei in jedes Mönches Belieben, zu heiraten in dem jedes Priesters. Auf weltlichem Gebiete fordert Luther Gesetze gegen den Kleiderluxus, gegen die massenhafte Einführung ausländischer Specereien, den Zinskauf, die grossen Handelsgesellschaften, das alte deutsche Laster unmässigen Fressens und Saufens, die Frauenhäuser: dann all-

36) Ebds., verkürzt. 
gemeine Sorge für den Jugendunterricht. Er verweist auf seine Worte über das Gerichtswesen im Sermon: die Spinnwebe fahen wohl die kleinen Fliegen, aber die Mühlsteine fallen durchhin. Neben dem Krieg erschienen ihm dort als das grösste Uebel die bösen Bestien, als Löwen, Wölfe, Schlangen, Drachen, dảs sind die bösen Regenten.

Dies waren Luther's Ideen von 1520. Ein neuer'Tag schien in ihnen über Deutschland aufzudämmern. Sie entsprangen aus einer Lage, in welcher eine reformirte nationale Kirche unter dem Papste noch möglich erschien. Die Herbeiführung dieser Reform erhoffte Luther damals nicht mehr von einem allgemeinen Concil, wohl aber von dem deutschen Reiche, von Kaiser, Fürsten, Adel und Städten ${ }^{37}$ ). Als Karl V. damals October 1520 nach Deutschland zu Krönung und Reichstag zog, rief ihm Hutten zu: "Tag und Nacht will ich Dir dienen ohne Lohn; manchen stolzen Helden will ich Dir aufwecken, Du sollst der Hauptmann sein, Anfänger und Vollender, es fehlt allein an Deinem Gebot." So bestand im Gemüthsleben der Nation ein inniger Zusammenhang zwischen dem Streben nach einer nationalen, stïndischen, starken Reichsregicrung, einer inneren Beseelung derselben durch das reine Evangelium und einer Einordnung des neuen Glaubens in sie. Die Denkschrift aus dem Schoos des Wormser Reichstags über die päpstliche Misswirthschaft und die kirchlichen Missbräuche stand schliesclich doch auf gemeinsamem Boden mit Luther's Schreiben an den Adel und mit Hutten's Flugschriften. Wäre eine Verwirklichung dieser Ideen Luther's möglich gewesen? Zu unserem Unglück war unsere kirchliche Reichspolitik von den auswärtigen Verhältnisisen zwischen dem Kaiser, dem französischen König und dem Papste bedingt.

Nun trat aber Zwingli neben Luther.

In Zwingli vollzog sich dieselbe Lmgestaltung des Christenthums in die selbständige Innerlichkeit der im Willen cinheitlichen Person. War in ihm nicht dieselbe trotzigfeste Originalität, so stand er eben darum mit der ganzen geistigen Bewegung der Zeit

35) Sermon W. 20, 267. 
in umso klarerem Einverständniss. Er nahm den religiös universellen Theismus und das von diesem bedingte Lebensideal auf das entschiedenste in den Zusammenhang des ächten Evangeliums auf, wie er dieses im Sinne des verbreiteten Augustinismus verstand, der ihn auf Paulus zurückführte. Eine erfrischende, männliche Gesundheit lebt in dem wohlgestalteten, heiteren, in seinem republikanischen Staatswesen tapfer wirkenden Manne, und strömt überallhin von ihm aus. In der reinen Luft der hohen Alpen erwachsen, in einer wohlhabenden Familie vom thätigsten und heitersten Gemeinsinn: fast noch als Knabe schon von dem Humanisten Wölflin und dem Theologen Wittenbach mit dem herzlichen Streben nach dem reinen einfachen Evangelium und zugleich mit der Freude an den grossen Alten erfüllt, sodass er später sagen durfte, was wir mit Luther gemeinsam haben, war schon unsere Ueberzeugung, ehe wir seinen Namen kannten: so ist er ohne inneren Kampf mit hellem männlichem Selbstgefühl dazu fortgeschritten; Zürich von dem katholischen Bischof loszureissen, das reine einfache Evangelium herzustellen, sowie eine Verbesserung der Sitten und der republikanischen Ordnungen der Schweiz hierdurch herbeizuführen.

Auch dem schweizerischen Reformator des Christenthums war der Mittelpunkt seines Glaubens die Zuversicht zu Gott, welche auf die Rechtfertigung durch den Glauben gegründet ist. Nur in der Kontinuität der Ueberzeugungen vollziehen sich die grossen sittlich religiösen Fortschritte. Er war früh in der paulinisch-augustinischen Rechtfertigungslehre durch seinen Lehrer Wittenbach gefestigt worden. Aber inmmitten der dem Augustinismus gemeinsamen Formeln tritt doch als ein ihm eigener Grundzug hervor, dass er Gottes Wirken in allem endlichen Geschehen gewahrt und auch der gläubige Mensch ihm eine aktive Kraft, ein Werkzeug Gottes ist. Dass vor Allem die Menschwerdung des Sohnes Gottes und sein Tod im Zusammenhang eines Rathschlusses steht, der mit der Schöpfung eines Menschen, der sündigen musste, begann, und seinen Mittelpunkt in der Offenbarung des Wesens Gottes, nämlich seiner Gerechtigkeit und Güte an die Menschen hatte. Alsdann dass in diesem nothwendigen Zusammenhang der Erlösung jeder einzelne durch die Gnadenwahl zum Glauben determinirt wird. Endlich dass dieser Gläubige 
durch die Gnadenwahl zum Werkzeug Gottes, der mit seinem Zweckwirken als das Gute die ganze. Welt erfüllt, unfehlbar und ohne Möglichkeit des Rückfalls wird. Eine grandiose Willensstellung! Indem sie den Menschen aller Wahlfreiheit beraubt, giebt sie ihm doch zugleich den höchsten. Werth, erfüllt ihn mit einem unermesslichen Selbstbewusstsein und mit der Zuversicht, das bewusste, willentliche und darum freie, von Gott gehaltene Organ des göttlichen Wirkens in der Welt zu sein. Eine lange ernste Reihe heroischer Naturen bis zu Cromwell steht unter dem Einfluss dieser Willensstellung.

Diese erangelische Willensstellung ist aber bei $\mathrm{Zwingli}$ in Zusammenhang mit philosophischen Ideen, die er in Plato und und seinem geliebten Seneca fand und für die ihm weiter die Humanisten ron der Florentiner Academie und Pico ab bis auf Erasmus, unter ihnen Pico voran, leitend gewesen sind ${ }^{38}$ ). Das Band, welches die beiden Ausgangspunkte Zwingli's von Anfang verknüpfte, liegt in der Fassung der Aufgabe der Philosophie bei Seneca und bei Pico. Bestimmte doch auch Seneca die Philosophie als Studium virtutis, war ihm doch ihr Ziel, durch die Vertiefung in das Allwirken Gottes, welcher Inbegriff des Guten ist, so-

3y) Zeller, Zwingli 1853 , bes. S. 11 hat auf den Einfluss der Stoiker auf Zwingli mit Recbt hingewiesen. Signart hat die schöne Entdeckung gemacht, dass insbesondere die Gotteslehre $Z$ wingli's durch Pico von Mirandola bedingt ist (Sigwart, Zwingli 1855, Einleitung). Wenn nun Ritschl, Lehre von der Rechtfertigung S. $151 \mathrm{f}$. Zeller rorwirf, ,er wolle bei den Reformatoren in erster Linie eine Lehre ron der Rechtfertigung entdecken, “ als ob „die Erkenntniss der reformatorischen Bedeutung von Zwingli und Luther schon durch die Varstellung und Vergleichung ihrer theologischen Systeme erschöpt wäre*: 50 hätte Zeller's Abhandlung Jahrb. 18.57 ibn von der Irrthünlichkeit dieser Voraussetzung überzeugen müssen. Das aber, was Ritschl wirklich von seinen Vorgängern trennt, die Aussonderung eines innerkirchlichen Lozirks leitender kirchlicher Personen, die Loslüsung dieser Personen vom allgemeinen Zusammenbang der Ideen und die ausschliessende Erfassung der religiösen und kirchlichen Kontinuität in ihrer Arbeit, ist, so böchst fruchtbar auch dio Durchführung seines Gesichtspunktes in Fortsetzung des nächstverwandten Nesader, der aber für die Organisation in der Kirche und ihrer Lehre zu wenig Sinn hatte, und in Ergànang der anderen Dogmenhistoriker sich erwiesen hat, doch mit der unhefangenen Interpretation der religionsgeschichtlichen Thatuachen nicht in Einklang. 
wie in cler frei willigen Hingabe an ihn, zur beata vita, der Seligkeit zu gelangen ${ }^{39}$ ). Vermögen wir auch nicht das Verhältniss der bildenden Kräfte in seinem reformatorischen Bewusstsein abzumessen: im Interesse einer wahrhaft geschichtlichen Betrachtung der Reformation muss anerkannt werden, welche durchgreifende Bedeutung der religiös universalistische Theismus für die freiere Gestaltung der reformirten Glaubensstellung gehabt hat. Gott ist Zwingli, im Geiste und vielfach mit den Worten Pico's, panentheistisch das alleinige Sein, das allumfassende Gut oder Gute: summum bonum. Da es nur Ein Unendliches giebt, folgt nothwendig, dass nichts ausserhalb desselben ist. So ist das Sein des Universums der Dinge das Sein Gottes selbst. Zwingli kann sich die Formel der Eleaten aneignen "Alles sei Eines". Bewegte sich etwas aus eigner Kraft, so würde es die Kraft der Gottheit einschränken ${ }^{40}$ ). Daher hat Plinius Recht, die Natur sei Gott. In Gott ist also alles Endliche gesetzt und determinirt. Die "menschliche Weisheit von dem freien Willen" ist uns von den Heiden eingeflösst. Aus der folgerichtigen panentheistischen Nothwendigkeitslehre ergiebt sich die Determination des Menschen zum Fall wie zum Glauben. Die Gnadenwahl, die vor dem Glauben stattfand, ist nicht dessen Folge, sondern sein Grund ${ }^{41}$ ). Und die Theodicee liegt so auch hier nur im Zusammenhang des göttlichen Weltplanes. Die stoische Lebensstimmung, an der Lektüre Senecas genährt, drückt sich in dieser Begründung der sittlichen Freiheit auf einen panentheistischen Determinismus aus. Indem der Mensch sich dem göttlichen Willen unterwirft, wird er von allem Aeusseren unabhängig. So zweifelt $Z$ wingli nicht, dass auch

39) Aus unzähligen Stellen hebe ich hervor epp. mor. 89, 108, dann 16, 110 de providentia vielfach, besonders I, 4 ff. Für die Freiheit des Christenmenschen bes. de vita beata 4 ff. - Ueber Pico's Auffassung der Philosophie Sigwart, Zwingli S. 16.

40) Quum unum. ac solum infinitum sit, necesse est, praeter hoc nihil esse. - Esse rerum universarum esse numinis est. - Si quicquam sua virtute ferretur aut consilio, jam isthic cessaret sapientia ac virtus nostri numinis. Zwingli, providentia $85 \mathrm{ff}$.

41) Electio non sequitur fidem, sed fides electionem sequitur. Qui enim ab aeterno electi sunt, nimirum et ante fidem sunt electi. Fid. rat. IV $7 \mathrm{~m}$. 
Heiden wie Sokrates und Seneca zum owigen Leben erwählt worden sind.

Dieser allgemeinen Determination durch Gott entspricht eine universelle Offenbarung Gottes. Religion ist Zwingli das Vertrauen des Kindes zum Vater, dass dieser Sorgen, Uebel und Böses zum Besten wenden werde ${ }^{42}$ ). Offenbarung ist ihm die innere Erleuchtung durch Gott, die diesen erkennen und nach seinem Willen leben lehrt. Diese Offenbarung ist an nichts Aeusseres gebunden, und sie ist nicht durch die Grenzen der Christenheit eingeschrïnkt. Haben heidnische Autoren walir geredet, so hat Gott es ihnen eingegeben, sonst wäre es nicht wahr $^{43}$ ). Aussprücho des Plato und Seneca sind göttliche Orakel. Diese Heiden haben aus dem Quell Gottes oder der Natur geschöpft. Seneca zumal mag unter den heiligen Schriften citirt werden "). Moses, Paulus, Plato und Seneca stehen als Zeugen bei ihm nebeneinander. Alles Wahre, Heilige, Gültige ist göttlich. „Wer die Wahrheit ausspricht, redet aus Gott."

Zwingli hebt weiter entsprechend seinem energischen Gottesberwusstsein, seiner Zuversicht der Gnadenwahl, seinem Glauben an die universelle Offenbarung Gottes viel entschiedener als die deutsche Reformation die ausschliessliche Kausalität Gottes in dem religiös sittlichen Process und dessen hieraus folgende Innerlichkeit herror. In dem grossen Bewusstsein der Macht Gottes und des Glaubens hat er auch diejenigen äusseren Hilfsmittel des religiösen Leben, an denen Luther's menschlich und ästhetisch reicheres und bereglicheres Gemüth noch hing, verworfen. Nichts als Innerlichkeit, Unsichtbarkeit, Wort, Leben, Energie in dieser

12) Ea igitur adbaesio, qua Deo, utpote solo bono, quod solum aerumnas nostras sarcire, wals omnis arertere aut in gloriam suam suorumque usum couvertere scit et potest, inconcusse fidit eque parentis loco utitur, pietas est, religio est. De rera et falsa rel. 1525. S. 50 .

4) Quod si quidam de boc quaedam vere dixerunt, ex ore Dei fuit, alioqui rerum non esset. De vera et falsa rel. 1525. S. If.

1) Peregrinum testimoniurn si adduxero, non protinus ad cujusvis damnationem consternabor, qui nondum perdidicit, literas tum sacras rito adpellari, quutn nuncient, quid sancta, pura, aeterns et infallibis mens sentiat. Irovid. 93. 
lichten, schlichten, hellen Kirche. Wie: er fest auf den Bekenntnissen der alten Kirche und der auf sie gegründeten paúlinisch augustinischen Rechtfertigungslehre stand, waren ihm Trinität und Menschwerdung die beiden Grundlagen seines ganzen Glaubenslebens. Doch schon in der Menschwerdung überwiegt ihm das sich Aufschliessen der Gerechtigkeit und Güte Gottes. Und bei jeder Erörterung der Trinität gilt es ihm vor Allem; die Einheit des göttlichen Wesens festzuhalten. So ist es tief im Geiste der Kirche Zwingli's begründet, dass aus ihi die Unitarier hervorgegangen sind. Da der Geist oder das innere Wort allein den Glauben erwirkt und ihn auch dort erwirken kann, wohin kein Buchstabe der Schrift gedrungen ist, so wird durch den Geist allein die Schrift aufgeschlossen und, ausgelegt. Der christliche Geist in Zwingli lehnt so ein ganzes neutestamentliches Buch, die Apokalypse, ab. Die Beimischung menschlicher Schwäche in der Gemeinde macht die Normirung durch die Schrift erforderlich. Schärfer als Luther gegen die kirchliche Tradition, selbst gegen das Herzliche, Gemüthvolle in ihr, neigt sich Zwingli der Regel $\mathrm{zu}$, dass nur was von ihr durch das innere Wort und die Schrift bestätigt ist, fortexistiren soll. „Der Gloub oder die Salbung empfindt in jr selbs, dass uns Gott mit sinem Geist inwendig sicheret; und dass alle die üsserlichen ding; die von ussen in uns kummend, uns nüts mögend anthun 'zu der rechtwerdung ${ }^{45}$ ). " Der Geist ist selbst Kraft und Wirken: er bewegt Alles: wie sollte er ein Vehikel bedürfen ${ }^{46}$ )? Den Sakramenten muss Zwingli die übernatürliche Wirkung, sonach auch die übernatürliche Beschaffenheit absprechen: sie sind Zeichen; Symbole. Gottesdienstliches Gepränge, Anrufung der Heiligen, Bilder von Christus oder Heiligen in den Kirchen ziehen das Gemüth ab von dem Unsichtbaren, von der ganz innerlichen aktiven Kraft Gottes in uns.

Diese ganze Welt von Innerlichkeit, Unsichtbarkeit, Wort, Leben, von Seele zu Seele in den bildlosen, dem Wort gewidmeten Bet- oder Predigthäusern sich mittheilend, wird nun aber sichtbar

45) Fründlich Verglimpfung. 1527 B IV.

46) Fidei ratio IV, 10. 
und wirksam in den Willenshandlungen der Christen in der Welt und der Gestaltung der menschlichen Gosellschaft nach dem christlichen Ideal. 'Und hier allein wird sie es. Das neue religiös sittliche Lebensideal, das dem Weltwirken zugewandt ist, spricht sich entschiedener noch als bei Luther in dem von Zwingli geschaffenen Lebenszusammenhang aus, nach welchem der Glaube eino aktivo Kraft ist, diese Kraft die Regel ihres Wirkens in dem Sittengesetz hat, und vermittelst ihrer der Mensch. zum Werkzeug Gottes in dessen Weltwirksamkeit wird. Das Gesetz ist der Ausdruck des Wesens Gottes, und so ist es als Bestandtheil der frohen Botschaft oder des Erangeliums in den Glauben eingeschlossen. Dor gesetzlichere Charakter der reformirten Religiosität, ihre durch ilın bedingte grössere Werthschätzung des alten Testaments und ihre Handhabung der Kirchenzucht treten an ihr überall, in England, Schottland, Nordamerika hervor. Zugleich eine grossartige Energie in der Gestaltung der menschlichen Gesellschaft nach den Principion des Glaubens, des Sittengesetzes, der Schrift: eine wahrhaft sociale Ethik.

Nun macht sich aber hier doch nur um so entschiedener bei Zwingli und den Reformirten eine schon bei Luther wahrgenommene Schwierigkeit geltend. Zwar wird in dem Begriff des Reiches Gottez und seiner wirksamen Glieder eine soziale, die Gesellschaft gestaltende Sittlichkeit gefordert. Aber gerade der religiös einzige Inhalt der Evangelien enthält doch nicht die erforderlichen teleologischen Principien für die Gestaltung der menschlichen Gesellschaft. Der nach diesen Principien lebendo Christ müsste nicht nur keinen Zins nehmen, sondern scin Eigenthum an die Armen vertheilen, er dürfte weder Eide leisten, noch das Schwert zichen oder Kriegsdienste leisten: Auch wurden diese Forderungen rings um Zwingli von den Taufgesinnten im Namen des apostolichen' Lebens erhoben. Der Ausweg, den Zwingli einschlug, ist oftmals seitdem verfolgt worden. Zwingli unterschied zwischen ciner inneren (idealen) Ordnung der Gesellschaft, dio zwischen wahrhaft Heiligen stattfinden könne, und einer äusscren, welche durch unsere Sünden geboten ist. Zumal die Eigentliumsrechte sind an sich unvollkommener sls die Gemeinsankeit des Be- 
sitzes, aber in dieser Welt voll Eigennutz sind sie unentbehrlich und wir können uns nur durch Wohlthätigkeit dem vollkommenen Zustande nähern ${ }^{47}$ ). Dieser Ausweg führt nicht überall zum Ziele. Dàs Eigenthumsrecht sichert ihre natürliche Sphäre eben jener aktiven Energie unseres Willens, in welcher wir der thätigen göttlichen Kraft auch nach $Z$ wingli ähnlich sind. Der Muth des Handelns, der sich in der Wehrhaftigkeit ausdrückt, ist keine Unvollkommenheit, verglichen mit dem Muth des Duldens, sondern ein Theil des ächt menschlichen Ideals. Das Christenthum hebt eben nur den transcendenten Bezug des Menschen heraus, als verschwände ausser Gott und der Seele alles Wirkliche. Die aus diesem transscendenten Bezug folgenden Begriffe, besonders der von der Brüderlichkeit aller Menschen, von ihrer Gleichheit vor Gott, ihrer Würde durch' ihre Gottähnlichkeit können als religiöses Erlebniss nicht überboten werden, ermangeln aber näherer Zweckbestimmungen, die eine Gestaltung des Lebens von ihnen aus ermöglichen würde. So bedarf also die Auffassung der Stellung des Menschen in den Quellen des Christenthums, um die soziale Gestaltung leiten zu können, einer Ergänzung von anderen Gesichtspunkten aus.

Dies bestätigt sich auch durch eine weitere Betrachtung. Darin hat Zwingli die Wahrheit gesehen, dass die Einrichtungen der Gesellschaft in einem christlichen Staatsganzen das Zusammenleben werdender Christen zur Aufgabe haben. Sonach müssen in den leitenden Principien eines christlichen Staates Regeln sein, welche aus diesem umfassenderen Verhältniss entspringen. Auch dies führt auf Principien einer sozialen Moral, in welchen die christlichen Ideen nur einen Bestandtheil bilden. Man kann in dem ausschliesslich transscendenten Bezug -der Menschen eine Einseitigkeit des Christenthums finden; man kann die Einseitigkeit aller Religion darin erblicken: jedenfalls haben Luther wie Zwingli vergebens gerungen, das vollere, allseitigere religiös sittliche Lebensideal, von dem sie getragen waren, auszugleichen mit den Quellen des Christenthums. Zwingli war hierin erfolgreicher als Luther. Besonders weil die Ideen

${ }^{47)}$ ' Stellen bei Zeller S. 187. 
der Alten und die politische Luft seiner Heimath ihn trieben, die fühlbarste Schranke der apostolischen Zeit zu überwinden. Nie darf die Geschichte Zwingli und der reformirten Kirche vergessen, was sie hierin leisteten. Sie hatten den Muth, auch auf so unzureichenden Grundlagen, trotz all der eben dargelegten Schwierigkeiten, trotz des Unvermögens, diese eben definitiv aufzulösen, für eine Umgestaltung der Gesellschaft und des politischen Lebens aus dem neueroberten christlichen Lebensstande heraus zu wirken. Sie zuerst haben die Sklavenfesseln zerrissen welche die christlicho Ueberlieferung von der Cüsarenherrschaft her trug: jene Regel der apostolischen Zeit rom widerstandslosen Gehorsam der stillen Gemeinden im Lande unter einer ihnen gleichsam fremden Obrigkeit. Sie zuerst haben dem neuen christlichen Geiste die Kiraft, die staatliche Ordnung zu gestalten, zuerkannt. Sie haben es als die Pflicht der Christen begriffen, mitzuwirken an der Gestaltung der obrigkeitlichen Verfassung. Der Staat bedarf nach Zwingli der im wahren Evangelium enthaltenen höheren Gesinnung: nur der wahre Christ verwaltet ein obrigkeitliches Amt richtig: eine Rogierung ohne Gottesfurcht ist Tyrannei: die Absetzung des Tyrannen durch den übereinstimmenden Willen des ganzen Volkes ist berechtigt" ${ }^{2}$.

Und hier greifen nun das Vorbild der apostolischen Gemeinden und die schweizerischen Verfassungen rings umher ein, um der reformirten Kirche die Richtung auf eine Gestaltung der politischen Ordnung zum republikanischen Systeme hin zu geben. Erkannte Zwingli in der christlichen Gesinnung die Regel der politischen Gestaltung der Gesellschaft, so ward ihm nun, auf Grund des eben bezeichneten Mangels umfassender Principien sozialer Sittlichkeit, die mit dieser Gesinnung in apostolischer Zeit entstandene Ordnung der Gemeinde zum Vorbild der politischen Ordnung. Ein Anfang von Bewegungen, welche, zumal mitgetragen von dem hinzutretenden naturrechtlichen Gedanken, Europa beinabe zwei Jahrhunderte hindurch erschüttert haben. So wenig sind

in Von Zwinglis Darlegungen sind besonders telehrend do vera et falsa religione 1525, S. $296 \pi$. und die l'redigt von menschlicher und götlicher Gerechligkeit. 1523 . 
Ideen blosse Begleiterscheinungen der politischen Veränderungen. Die Selbstregierung des christlichen Volkes ist nun das Ideal der reformirten Christen bis in das Zeitalter Cromwell's und seiner Geiter geworden und dieses Ideal hat an der Umgestaltung des politischen Systems von Europa noch bis zur Revolution von 1688 mitgewirkt.

Fassen wir noch einmal das Grosse in Luther und Zwingli zusammen, wodurch sie damals Alles mit sich' fortrissen. Ein neues sittlich religiöses Lebensideal. Ein in das Unanschauliche, Innerliche, Unabhängige umgewandeltes Verhältniss der Person zu dem Unsichtbaren, das sie umgiebt. Sie erfassen den Glauben als einheitliche, zuversichtliche Willensverfassung der Person, gegründet auf ihren realen Zusammenhang mit dem Unsichtbaren: die äussere Disciplin des alten priesterlichen religiösen Processes, die so lange auf der Menschheit gelastet und ihr ganzes Leben umspannt hatte, thuen sie entschlossen von sich. Aus diesem Glauben quillt eine aktive Energie der ganzen Person, deren Funktion das volle Leben in der Welt, die sittliche Gestaltung aller concreten Lebensverhältnisse, ja die Reformation des gesammten bürgerlichen, politischen und religiösen Lebens der Gesellschaft ist. Und so wird ihnen diese religiös, bürgerlich und politisch geordnete Gesellschaft zum Körper des christlichen Geistes: sie verwerfen die mittelalterliche Theilung des Regimentes über die Welt in die beiden Reiche: die abgelebten Ordnungen werden im Namen der tiefen, neu errungenen christlichen. Lebensstellung von ihnen überall erschüttert und theilweise zerstört.

Aber fassen wir auch noch einmal zusammen, warum nun aus dieser neuen Willensstellung des Menschen nicht in gerader Linie die erstrebte Neuordnung der kirchlichen, bürgerlichen und politischen Gesellschaft sich ergab. Die neue religiöse Formation enthielt so wenig, als das Christentham des apostolischen Zeitalters, auf das sie sich stützte, ausreichende Prinzipien zur Gestaltung der Gesellschaft. Eben aus dem apostolischen Christenthum hatte der römische Herrschergeist das katholische Kirchensystem entwickelt. Er hatte für die tiefinnerliche, weltabgewandte Lebensstellung so eine wirksame Organisation angestrebt, durch welche sie die Herr- 
schaft über die Welt gewönne. Ein ungeheurer Widerspruch! Derselbe musste sich in der Verweltlichung dieser geistlichen Organisation geltend machen. Er ward im Innern derselben von den tiefsten Geistern jeder Zeit tragisch empfunden. Die Reformation hebt ihn auf. Aber wird sio nun vermögen, aus sich heraus eine Ordnung der Gesellschaft zu gestalten, die ihr ontspricht?

Zunächst crzittert unter dem Einfluss der neuen Ideen der ganzè Boden des alten Reiches nördlich bis in die Niederlando und südlich bis in die Schweiz. Gewiss, so wenig als die Ideen der französischen Aufklärung die Revolution hervorgebracht haben, sind durch Luther's und Zwingli's Predigt und Schriften die Bauernkriege und die täuferischen Aufstände herbeigeführt worden. In dem einen wie in dem anderen Falle war es ein unerträglicher Druck, der die revolutionären Kräfte entband. Aber in jedem der beiden Fïlle haben die neuen Ideen der Bewegung ein höheres Recht mitgetheilt und ihr die Bahn gewiesen. In dem ersteren Falle überwog in der Bewegung der Kampf um die geistige Selbständigkeit, welchen die Laien gegen die geistliche Klasse führten. In dem anderen Falle überwog der Kampf um die politische Freiheit, welchen das Volk gegen die Fürsten und den Adel fübrte. In beiden Fällen sind dann unter Berufung auf diese leitenden Ideen Eingriffe in das bestehende Recht ohne Zahl vollzogen worden. Die Reformation kann in Bezug auf die Gewaltakte, die damals in ihrem Namen begangen wurden, auf die krankhaften Zuckungen, die in ihrem Gefolge, auftraten, weder einfach verantwortlich gemacht, noch einfach freigesprochen werden. Auch wirkten in diesen revolutionären Vorgängen nicht allein dic schlimmen Eigenschaften der menschlichen Natur, die überall auftreten, wo die gewohnten Regeln der Geschäftsführung versagen, der einformige Gang bürgerlichen Lebens durch das Ausserordentliche unterbrochen wird, Verbannte von Stadt zu Stadt ziehen, rechtlos gewordene Existenzen, wie hier entlaufene Mönche und brotlose Priester auftreten. In den Grundsätzen des neuen Evangeliums selbst lagen erhebliche Gründe für die Ausschreitungen. Diese Grundsätze waren sehr verschiedener Deutung fähig. Sic wurden in Augsburg anders gefast, als in Basel und in Zürich 
anders' als in Strassburg. 'Und unzählige Schattirungen derselben bekïmpften einander, zumal , in den Reichsstädten. Sie riefen grenzenlose Erwartungen hervor. Aber sie enthielten, wie wir sahen, kein zureichendes Princip, die erhoffte Neuordnung der Gesellschaft in festen Grenzen zu gestalten.

Die neu errungene Lebensverfassung hatte das Christenthum des apostolischen Zeitalters überschritten. Sie fand also in dem Beweis aus der Schrift keine zureichende Grundlage mehr. Sie stand mit dem Neuen in sich auf der Macht und dem Recht der religiösen Erfahrung. Sie hatte mit dem Satze, dass der lebendige religiös sittliche Process des Glaubens nicht etwa nur der Erkenntniss des Unsichtbaren und seiner Bezüge zu uns vorausgehe, sondern eben dies lebendige Wissen in sich fasse, das dann keiner weiteren Aufklärung fähig sei, die Grenzen des bisherigen metaphysischen Standpunktes überschritten. Aber Dunkelheiten umgaben sie nun ringsum. Welches ist das Verhältniss des inneren Wortes zu der dogmatischen Symbolschrift, in welcher die dogmenbildenden. Concilien es fixirt haben? In welchem Umfang sind neben den religiösen Formen unseres Bewusstseins vom Unsichtbaren die philosophischen berechtigt? Muss man nicht von der christlichen Gestalt des höheren Lebens auf die Bedingungen derselben in der immer gleichen Menschennatur, in der Psychologie, Selbstbesinnung, Erkenntnisstheorie zurückgehen? Andererseits ergänzende Principien für die Gestaltung der Gesellschaft aus den anderen Kultursystemen derselben entnehmen? Fragen, vọn denen die Aufklärung und Begränzung dieser neuen subjectiven Lebensverfassung abhing. Noch war die ungeheure Macht subjectiver Selbstgewissheit und Lebenszuversicht in diesem neuen Standpunkt nicht mit der entsprechenden klaren Reife und Gestaltungskraft verbunden. In der protestantischen Gemeinde lag das Princip des inneren Wortes mit dem der Schrift im Streit: die Evangelien mit Paulus: das apostolische Leben mit den Menschen wie sie sind: das christliche Ideal mit der Staatsraison: vor Allem doch das, Wort der Bibel mit der in der Reformation fortgeschrittenen Gestalt des religiösen Lebens.

Und nun trat ein neues Moment allgemeiner Unsicherheit, revolutionären Ringens hinzu. In derselben Zeit, in : welcher die 
neuen Ideen überall in Deutschland siegreich vordrangen, war dio einheitliche Aktion des Reiches in Bezug auf dieselben gelähmt. Ebenso rerschärfte sich in der Schweiz der Gegensatz zwischen den Urkantonen und den protestantischen Bezirken und erschion unüberwindlich; auch hier rang man vergeblich nach einer cinheitlichen Regelung der Reform in dem Ganzen der Eidgenossenschaft. Die einheitliche Leitung der grossen Bewegung war nicht herbeizuführen.

Dies waren die Bedingungen, unter welchen eine Bewegung, in welcher alle fortschreitenden Kräfte vereinigt gewesen waren, die wie ein glühender Lavastrom nach allen Seiten sich ergossen und Alles mit sich fortgerissen hatte, etwa seit $1524 \mathrm{zu}$ erstarren begann. Die Kirchenbildung war nun in die Territorien verlegt, das Ideal einer das Reich umfassenden religiösen Reform entwich in nebelhafte Fernen. Für die Anhänger des neuen Glaubens war nach der Verneinung der Autoritit von Concilien und Päpsten kein Richter und keine Norm der Auslegung von Schrift und Glaubenserfahrung da. Alle Schwierigkeiten, mit denen der Protestantismus bis heute ringt, waren damals sogleich da. Und in dieser freien Mannichfaltigkeit persönlicher Ueberzeugungen hat er doch trotz all dieser Schwierigkeiten sein Leben. Das Nächstliegende wäre gewesen, dass die Bewegung sich mit evangelischer Freiheit in Gemeinden und kleinen Verbänden ausgebreitet hätte. Dies hätte aber die religiöse Gährung permanent gemacht. Es widersprach dem Verhältniss eines religiösen Genius wie Luther zu den glaubesuchenden autoritātsbedürftigen Menschen, wio sio nun cinmal sind. Es hātte klare Principien der Fortgestaltung der Gesellschaft in dem evangelischen Glauben vorausgesetzt, denen man sich ruhig anvertrauen konnte. Ich habe dargelegt, dass solche klare Grundsätze aus dem Rückgang auf die Bibel nicht abgeleitet werden konnten. Dem Chaos von Forderungen und Träumen, die auf Grund des ächten Evangeliums von den Täufern, den Spiritualisten in den Stijdten, den sich erhebenden Bauern auf dem Lande erhoben wurden, trat Luther festen Herzens, doch mit dem äusserlichen und harten Grundsatz vom göttlichen Rechte der mit dem Schwert betrauten Obrigkeit gegenüber, welcher aus dem Dualismus stiller 
Gomcinden und einer heidnischen Obrigkeit stammte. Ebenso fohlten dem Protestantismus gemeinsame Grundsätze für die Kirchenbildung, und unvermittelt standen die Ordnung der Kirche aus der Einzelgemeinde, vermittelst der Synoden und durch die obrigkeitliche Kirchengewalt nebeneinander. So entschied Luther's religionsbildende, kirchenbildende Persönlichkeit mit ihrem festen christlichen Gehalt. Er hielt sich an das Nicenum. Er trennte sich von Zwingli. Er sagte sich von Erasmus los. Er überliess die Spiritualisten der Verfolgung. Er gründete in den deutschen protestantischen Territorien seine Kirche.

Die Danaidenarbeit der theologisch-metaphysischen Systembildung begann in" dieser Kirche von Neuem. Da sie den religiösen Tiefsinn Luther's in sich barg und diesen nun von Melanchton ab mit der Anerkennung der Alten, dann seit Leibniz mit dem modernen Denken in Verhältniss zu setzen strebte: sind aus diesem Nacherleben der geschichtlichen Standpunkte in ihrer unverkürzten Eigenheit die Geschichtlichkeit des deutschen Denkens, das universalhistorische Verständniss, die Transscendentalphilosophie entstanden. Aber von dieser nun entstehenden Kirche trennten sich Erasmus, Staupitz, Willibald Pirkheimer, Ulrich Zasius, Sebastian Franck und viele andere weniger hervorragende Personen, wie man sie in dem ersten Bande von Döllinger und dann bei Janssen in längem Zuge aufgeführt findet. Dieselbe verengte und verhärtete sich. Und zunächst vollzog sich in Personen, die sich Luther unabhängig gegenüberstellten, sowie in den von $Z$ wingli ausgehenden Kirchen und Sekten, auf Grund des dargelegten intimen Verhältnisses von Zwingli zu der allgemeinen geistigen Bewegung und des von ihm zur Geltung gebrachten Gemeindeprincips, der theologische Fortschritt des 17. Jahrhunderts: an sie schloss sich dann auch die philosophische Bewegung vorwiègend an.

Und zwar sind, schon im. Zeitalter der Reformatoren aus dem. Zusammenwirken der, dargestellten geistigen Kräfte die beiden Hauptrichtungen der Theologie entstanden, die sich in dén folgenden Jahrhunderten mit der orthodoxen in die Herrschaft theilen 'sollten: die rationalistische 'und die speculative oder transscendentale. Die Anfänger dieser, beiden Schulen ge- 
hörten der deutschen Zunge an, standen aber ausserhalb der Kirche Luther's.

Erasmus ist der Begründer des thoologischen Rationalismus. Unter diesem verstehe ich die souveräne Reflexion des Verstandes über den Glaubensinhalt, durch welche dieser in ein Verhältniss von Gott, Christus, Mensch, von freiem Willen und Einwirkungen Gottes, als von lauter einander fremden Selbständigkeiten zerlegt wird. Hiezu tritt dann durchgängig ein starkes Bewusstsein ron den Grenzen des Verstandes, welches von Erasmus' als sein Skepticismus bezeichnet wird. Dieser theologische Rationalismus entwickelte sich aus der humanistischen Aufklärung, wie sie namentlich von Laurentius Valla und von Ludovicus Vives vertreten wurde. Und sein erstes classisches Werk war die Schrift des Erasmus de libero arbitrio, welche dieser nach längerem Zögern 1524 veröffentlichte. Sie behandelte. den Cardinalpunkt der Glaubenslehre Lather's. Dessen Gegenschrift de servo arbitrio erschien im December 1525. Worauf dann wieder Erasmus in Gegenschriften erwiderte, die zu der ersten Darstellung seines Standpunktes nichts erheblich Neues hinzubringen.

Es ist nicht möglich, bei Erasmus das was er in seiner Position, auch in der finanziellen, für erforderlich hielt, von dem zu sondern, was seine Ueberzeugung war. Sicher vermochte Luther dem Vielköpfigen und mit allen Farben Schillernden in diesem Voltaireschen Genie nicht gerecht zu werden, und scine Aeusserungen über ihn gehen fehl, deren schärfste die in den Tischreden ist "). „Erasmus ist ein Feind aller Religion und ein sonderlicher Feind und Widersacher Christi, ein vollkommen Conterfeit und Ebenbild Epicuri und Luciani." Aber wenn Erasmus von vornherein sein Buch de libero arbitrio dem Richterspruch der Kirche unterwirft, so ist das eine Accommodation des ersten Rationalisten. Diese Accomodation reicht aber weiter. Wenn er die Bibelstellen gegeneinander abwăgt und die paulinischen Stellen ganz so gelten lasst als die der Evangelien, so ist die Bevorzugung der Stellen der Evangelien doch merklich: er muss auch gesehen

4) Tiscbreden, Förstemann, II 419. 
haben, dass hier ein Widerspruch besteht und dass ihm die Stellen der Evangelien günstiger sind. Hebt er doch sonst den Unterschied des allein irrthumsfreien Christus und der zuweilen irrenden Apostel hervor ${ }^{30}$ ). Iie Apokalypse spricht er nicht nur dem Johannes $a b$, sondern er hat den Cerinth im Verdacht, sie eingeschmuggelt $z u$ haben. Und das Markusevangelium scheint ihm ein Auszug aus dem Matthäus zu sein. In all diesem ist sein enormer Spürsinn auf dem Weg der rationalistischen Kritik. Neben ihm hat Agrippa von Nettesheim in seiner genialen Schrift auf die Mängel unserer Quellenkenntniss des Christenthums hingewiesen: habe doch eine Menge von Evangelien bestanden und sei verloren gegangen. So würde man dem Erasmus Unrecht thun, die Annahme von. Gleichwerthigkeit biblischer Stellen nach dem Zuschnitt damaliger dogmatischer Erörterungen bei ihm vorauszusetzen. Er accommodirte sich.

Die Schrift stellt zuerst den leitenden Gesichtspunkt auf, welcher eine vorsichtige praktische Haltung dem Problem gegenüber erforderlich macht. Alsdann erörtert sie den Widerspruch zwischen den biblischen Stellen, welche die menschliche Freiheit behaupten oder voraussetzen und den anderen, welche Gottes ausschliessliches Wirken in dem Beseligungsprocess ausdrücken. Endlich unternimmt sie diesen Widerspruch aufzulösen und die Cooperation der Freiheit und des göttlichen Wirkens festzustellen.

Willensfreiheit definirt Erasmus als die „Kraft des menschlichen Willens, vermöge deren der Mensch sich dem zuwenden kann, was zum ewigen Heil hinführt, oder von demselben abwenden " ${ }^{51}$ ). „Es kann nun zunächst nicht geleugnet werden, dass in den heiligen Schriften eine grosse Anzahl von Stellen ist, welche den freien Willen des Menschen ganz deutlich zu statuiren scheinen ${ }^{52}$ )." Neben den ganz klaren einzelnen Evangelienstellen hebt er besonders hervor, dass die Vorschriften Christi überhaupt

50) Zu Matth. II p. 7. Opp. VI p. $610 \mathrm{~B}$.

51) de lib. arb. 12. 17. Porro liberum arbritrium hoc loco sentimus vim humanae voluntatis, qua se possit homo applicare ad ea quae perducunt ad aeternam salutem, aut ab iisdem avertere.

52) Ebds. p. $27 \mathrm{ff}$. 
Leben und Wirksamkeit verlieren, wenn dem freien Willen keine Kraft gelassen wird ${ }^{33}$ ). Auf der anderen Seite wird ihm dann schwer, die Beweiskraft der paulinischen Stellen gegen den freien Willen, die er offen anerkennt ${ }^{54}$ ), wenigstens $z u$ mindern ${ }^{35}$ ). Die Auflösung dieses Widerspruchs liegt zunächst in der Erkenntniss, dass von der Betonung des moralischen Motivs, zur Selbstthätigkeit anzufẹern und Zutrauen zu erwecken, die Einen Stellen bedingt sind, dagegen die anderen von der Betonung des religiösen Motivs, im demüthigen Gefühl der Abhängigkeit von Gottes Wirken diesem alles Verdienst zuzuschreiben.

Es sind also nur die zwei Seiten desselben Vorgangs, die in diese zwei Classen von Stellen einseitig hervorgehoben werden. Die Existenz des göttlichen Allwirkens leugnet nun Niemand. Aber auch die Thatsache des freien Willens sollte keinem Zweifel unterworfen werden. Erasmus entwickelt das ganz überzeugend und schärft es immer wieder ein: die Begriffe von Vergeltung, Strafe, Verdienst und Gericht sowie die Existenz des Gewissens und der in den heiligen Schriften wie im biblischen Bewusstsein auftretenden Vorschriften, Drohungen, Versprechungen haben allesammt die Freiheit des Willens zu ihrer Bedingung. Ja er zeigt scharfsinnig, dass selbst die specifisch religiösen Begriffe der Hilfe und Unterstützung Gottes, des Verdienstes, des Gebets die menschliche Freiheit" fordern. Und Niemand nach ihm hat beredter dargethan, dass die Gnadenwahl denselben Gott, der den Erwählten barmherzig sich erweist, den Ausgeschlossenen gegenüber zu einem grausamen Tyrannen macht. Der Gott, der Gesetze giebt, damit sich erweist, dass der Mensch sie nicht halten kann, ist noch tyrannischer als jener Tyrann von Syrakus, der seine Gesetze gab, um die Uebertreter strafen zu können. Der Beweis, dass der altchristliche Begriffszusammenhang, den die Erangelien geben und der in dem Gewissen der Christen immer wieder erfahren wird, die Freiheit des Willens schlechterdings als Voraussetzung fordert, ist von Erasmus mit siegreicher Kraft Luther gegenüber geführt worden.

i) p. 35.

4) Ebds. p. Gf.

s) Elbds. p. 66 fr. 
Nun aber entsteht die Frage, wie diese Thatsache sich mit der des Allwirkens Gottes in Einklang bringen lasse: und hier macht sich nun das Unvermögen des Rationalisten, diesem $\mathrm{Zu}$ sammenhang sein Recht widerfahren zu lassen, geltend.

Es findet eine "Cooperation zu dem untheilbaren Werk" der Wiedergeburt statt. Und zwar so, dass die Gnade die causa principalis ist, die menschliche Freiheit nur die causa secundaria ${ }^{56}$ ). Dies wird zunächst damit erläutert, dass dem Feuer eine Kraft zu verbrennen einwohnt und dass diese doch zugleich zu ihrer principalis causa Gott hat, welcher durch sein Wirken im Feuer dessen Brennkraft erhält. Aber durchweg läuft es vielmehr auf das auxilium und die mechanisch äusserliche Cooperation Gottes mit dem freien Willen hinaus. Ein Vater zeigt einem Knaben, der noch nicht zu laufen vermag, einen Apfel; der Knabe, der zu ihm hinstrebt, wird von dem Vater mit der Hand vorwärts geleitet: dies ist ein anderes und den Ideen des Erasmus mehr entsprechendes Gleichniss. Kann es aber eine äusserlichere und gröber mechanische Vorstellungsweise geben?

Von dieser mechanischen Betrachtung aus, nach welcher der Wille des Menschen und das Wirken Gottes concurrirende Kräfte sind, können natürlich die ohnehin metaphysisch unlösbaren Probleme des Verhältnisses von Präscienz, Providenz und Allwirksamkeit zur Willensfreiheit 'schlechterdings nur in sinnlicher Verstandesflachheit behandelt werden. Ein Herr kennt die schlechten Neigungen seines Sklaven und stellt ihn an einen Platz, wo der Sklave diesen gemäss schlecht handelt; so dient sein Fall den anderen Sklaven zum, warnenden Beispiel. Ist es möglich, flacher zu reden? Und doch erscheint auch hier der bon sens des Erasmus gegenüber Luther in seiner ganzen Stärke, indem er immer wieder räth, an die Thatsachen der inneren Erfahrung sich zu halten, und jeden Versuch, den Zusammenhang derselbeñ in die unerforschlichen Tiefen des Metaphysischen zu verfolgen, mit, dem gesunden Skepticismus abweist, der jenem Zeitalter das kritische Bewusstsein vertrat.

56) Ebendaselbst p. 81 . 
Und von diesem rationalistischen, historisch kritisch festgegründeten Standpunkt aus begann nun auch schon Erasmus die Dogmatik zu unterminiren. Vorsichtig, aber mit stillem, hartnäckigem Hass. Er bemerkt, in wie wenig Stellen Christus als Gott bezeichnet werde und dass der heilige Geist nirgend diese Bezeichnung erhalte: so erschütterte er die Trinitätslehre ${ }^{57}$ ). Und Melanchthon schrieb der stillen Wirkung des Erasmus. den Abendmahlsstreit zu ${ }^{58}$ ). Von Erasmus geht Eine gerade Linie zu Coornhert, za den Sozinianern und Arminianern, von da zu den Deisten.

Neben die orthodoxe und die rationalistische Theologie trat die speculative oder transscendentale. Das Merkmal derselben liegt darin, dass sie in der Geschichtlichkeit der einzelnen Religion, insbesondere des Christenthums den Ausdruck eines Bewusstseinszusammenhangs sieht, welcher ewig in der Natur des Menschen und der Dinge gegründet ist. Dies ist ihr nur möglich, indem sie als Schlüssel für das Verstïndniss der religiösen Begriffe ron Offenbarung, Inspiration, Gnadenwahl, Rechtfertigung jenen religiös universalen Panentheismus anwendet, dessen Einfluss wir bis hierher verfolgten und der nun auch Luther's positivistischem Tiefsinn gegenüber - sagen wir es heraus! - siegreich vorwärts dringt.

Die moderne speculative Theologie hat sich aus der Mystik entfaltet. Denn das ist nun doch in dieser ganzen kampferfüllten Religionsepoche der Kern alles Ringens gegeneinander: die uralto in der Menschheit unermesslich wirksame Opferidee, welche sich seit Paulus des Christenthums bemächtigt hatte, ist von Luther zwar als Nittelpunkt des Cultus in der Messe sammt dem an ihr hāngenden altrōmischen Priesterbegriff verneint, aber sie ist doch von ihm noch einmal in jenen Dogmen ersten Grades, der eigentlichen religioisen Bilderschrift, welche der systematischen Theologenarbeit vorausgehen, als Centraldogma herausgehoben worden. Ihr aber tritt nun der mystische Begriff der forma dei im Menschen ent-

ni) Ilierfür instruktir die seine ideale Ceberzeugung nur leicht verachleiernde Vertheidigungsschrift adversus Sonachos quosdam llispanos 0 rp. $4,10,23$.

sey Corp. ref. 1 10s3.

Arebir C. Gearbiabie d. Pbisonoptice $v$. 
gegen. Und ihm gehörte die Zukunft. Kant, Schleiermacher haben ihn zum Siege geführt. Die neutestamentliche Kritik hat die Abwesenheit dieses Opfergedankens im ursprünglichen Christenthum aufzeigen können.

Erfassen wir die Anfänge hiervon. Seitdem eine einheitliche Leitung der religiösen Bewegung nicht mehr von dem Reichsregimente erhofft werden konnte, regten sich die elementaren religiösen Kräfte, die Handwerker in den Städten, die Bauern. Als der Bauernkrieg niedergeschlagen war, treten die evangelischen Taufgesinnten unter den Handwerkern der Städte hervor. Ihr Ursprung ist nicht einfach. Die seit dem Auftreten der Waldenser in verschiedenen Formen fortbestehende, auf apostolisches Leben gerichtete populäre Bewegung, das Wirken der Franziskanerpredigt von der Nachfolge Christi sowie von der Nachbildung seiner Lebensform und nun die alles Weltliche und Geistliche umfassenden Reformideen wirkten zusammen. Indem diese Gemeinden auf das innere Wort und das apostolische Leben zurückgingen, leiteten -sie aus der christlichen Gleichheit und Bruderliebe die Gütergemeinschaft und die Aufhebung von Zinsen und Zehnten ab, aus den Worten Christi die Verweigerung von Eid und Kriegsdienst, aus der Lehre vom inneren Worte die Verwerfung der sakramentalen Taufwirkung und sonach der Kindertaufe. In der Schweiz traten diese Täufer zuerst etwa seit 1522 auf, wurden aber. von Zwingli niedergeschlagen: Dann erschienen sie unter der Führung von Hubmaier, Denck, Hetzer, Grebel seit 1526 in Oberdeutschland. Sie hatten meist zu den Anhängern Luther's oder Zwingli's gehört, in Augsburg, Nürnberg, Strassburg giebt es von ihnen zu Zwingli und von da zu Luther Schattirungen aller Art, ihre Zahl war ausserordentlich gross und sie mischten sich überall mit den anderen Evangelischen. Die grausame Verfolgung gegen sie durch Zwingli und Luther war eine der Ursachen für den Rückgang der Reformation und bewirkte zugleich den furchtbaren Ausbruch des münsterischen Aufruhrs, den man nur mit der Jakobinerherrschaft während der französischen Revolution vergleichen kann. Die Entscheidung gegen die Taufgesinnten ist durch die äussere politische Macht herbeigeführt worden: eine Nothwendigkeit schon darum, 
weil ein Protestantismus ohne Widerstandsrecht und Schwert verloren gewesen wäre!

Diese Bewegung mischte sich vielfach mit den aus der wissenschaftlichen Gährung entstehenden $Z$ weifeln gegen Dogma und heilige Geschichte. Anfang des Jahrhunderts ist in den Niederlanden ein Ketzer, Hermann Rysswick, verbrannt worden, welcher die averrhoistischen Ideen vortrug: zugleich leugnete er, dass Gott dem Moses erschienen und Christus Gottes Sohn sei, erklärte vielmehr Christus für einen Phantasten: „unser Glaube ist ein lauter Tandmär und Fabel ${ }^{(59}$ ). Einige Männer aus Antwerpen setzten 1525 persönlich Luther auseinander, der heilige Geist sei nichts als die Vernunft und der Verstand ${ }^{60}$ ). In Nürnberg suchten neben den Atheisten sich Deisten, welche das ganze positive Christenthum ablehnten, geltend zu machen; in dem höchst interessanten „Process gegen die gottlosen Maler" Georg Penz, Sebald und Barthel Behaim trat dieser letztere Standpunkt entschieden hervor; so hatte Barthel die evangelischen Erzählungen von Christus mit der Sage über den Herzog Ernst verglichen, der in einen Berg gefahren sein solle ${ }^{61}$ ).

Welche Revolution in allen ererbten Ideen ringsum im deutschen Lande! Karlstadt, der rastlose Kämpfer gegen die neuentstehende Luther'sche Theologie und gegen Luther's Abendmahlswunder, rerworren, genialisch, von Eifersucht gegen den überlegenen Luther erfüllt: schon 1520 war ihm zweifelhaft geworden, ob die Bücher Mose auf diesen als Autor zurückzuführen scien und die Evangelien in ihrer ächten Gestalt auf uns gekommen; er hatte 1521 den Wittenberger Studenten gerathen, die Auditorien zu verlassen und das Land im Schweiss ihres Angesichts zu bebauen, wie Rousseau oder Tolstoi; dann später hat er seinen priesterlichen Ornat ausgezogen, man sah ihn in Bauernkleidung umberziehen. IIüzer, ein anarchistischer Gewaltmensch: auch er vertritt gegen

sy Sebastian Franck, Cbronik 1331. Fol. $406 \mathrm{f}$.

*) Luther an die Christen zu Antwerpen. De Wette 11160.

5) Luther an Brismann 4. Februar 1525 bei de Wette 11 623. Aus der. selben 7eit Pirkheimer bei Strobel, Beitrăge zar Litt 1 496. Der Process bei Basder, Beiträge II $52 \mathrm{t}$. und in der Beilage, wo er abgedruckt ist. 
Luther die Mystik, das apostolische Leben, dessen Gütergemeinschaft; aber er will mit Blut und Eisen das neue Friedensreich herbeiführen. In der Schrift wider das sanftlebende Fleisch in Wittenberg greift er Luther an seinen schwächsten Punkten an, er verwirft die Selbstverachtung im Dogma von der Sünde und dem unfreien Willen, und er verspottet die neuen logischen Kunstgriffe, durch biblische Stellen von dem göttlichen Rechte der Obrigkeit das arme Volk niederzuhalten. Dann Kaspar Schwenkfeld, Michael Servede, Campanus, Hubmaier, Hetzer: wohin man blickt, eine trübe Flüssigkeit von Grübelei über Trinität, Gottmenschheit, Rechtfertigung, Sakramente, apostolisches Leben. Ueberall aber auch die grosse fortschreitende Tendenz, im Sinne des Luther von 1520 die persönliche Innerlichkeit des religiös sittlichen Vorgangs, das moralische Vermögen des Menschen, die reformatorische Kraft des wahren Glaubens gegenüber der ganzen bestehenden Gesellschaft in ihren weiteren Consequenzen zu entwickeln, auch gegenüber der sich nun bildenden Kirche Luther's: vielfach der Fortschritt in der Erfassung des Christenthums von Paulus.zu dem Christus der Evangelien: und vielfach auch das Ringen, den 0 pfergedanken, welcher von den abgelebten Formen der Religiosität her auf der Menschheit gelastet hatte und nun doch auch in Luthers paulinischem Christenthum wieder eine centrale Stellung besass, endlich abzuschütteln. Dazu machte sich an vielen Stellen die unitarische Richtung geltend.

Diese Bewegung trat nun in einigen Personen von entschiedener Begabung in Verbindung mit humanistischer, mit allgemein wissenschaftlicher Geisteshaltung; insbesondere die Vertheidigung der Freiheit des Menschen durch Erasmus wurde acceptirt: so entstand eine besondere speculative Form des religiös univorsalen Theismus und der mit ihm verbundenen Lehre von der religiös moralischen Selbständigkeit des Menschen gegenüber jeder kirchlichen Tradition und Heilseinrichtung.

Hans Denck begründet die christliche Ueberzeugung auf die innere.Stimme, das Gewissen und das religiöse Gefühl: hierin ist ihm ein Funke des göttlichen Geistes selbst. Dieser Geist ist also unabhängig von der heiligen Schrift überall wirksam. Er wohnt 
in allen Menschen. Die Geltung der Schrift kann nur aus ihm erwiesen werden. Aus dem Leben in der Nachfolgo Christi kommt aller Glaube. Ungläubig sind die, welche sich selbst suchen. Und zwar geht er von Paulus auf die Evangelien, auf die Wrorte Christi selbst wie Erasmus .zurück, insbesondere auf Johannes. Der Mensch hat nach Dencks Schrift über dio Ordnung Gottes in sich den Willen zum Guten, einen Funken des göttlichen Geistes. Er hat einen freien Willen. Indem er sich selbst sucht, entsteht in ihm die Entzweiung mit Gott, die Hölle, der Unglaube. Nun ist sein Wille gefangen, und nur mit der Hilfe Gottes vermag er die Vereinigung seines Willens mit dem göttlichen wieder zu erlangen. Selbstverleugnung, das Verlieren seiner selbst, ist der Weg zu dieser Vereinigung. Aus diesen Gedanken heraus bekämpft er Luther's Rechtfertigungs- und Versöhnungslehre. Die Gesetzescrfüllung Christi hat den Zweck, uns den Weg zur Nachfolge zu bahnen ${ }^{63}$ ). Er verwarf die ewigen Höllenstrafen, ja scheint auch die Existenz des Teufels, der Luther so viel zu schaffen machte, bestritten za haben.

Aus diesem revolutionären Chaos erhebt sich ein wahrhaft genialer Denker und Schriftsteller, Sebastian Franck, zu ciner geklirteren, geschichtlich weiten Fassung dieses Standpunktes.

Ein Schwabe, etwa 1500 in Donauwörth geboren; er scheint eine sehr mïssig geleitete Vorbildung genossen $\mathrm{zu}$ haben: doch im Gefühl des angeborenen Berufs wagte er, die Laufbahn des Schriftstellers zu ergreifen. Er begann mit Uebersetzen, Bearbeiten von Vorhandenem in deutscher Sprache, Zusammenstellen, und an dieser Art von Thätigkeit hat er immer festgehalten. Das Theologische stand natürlich im Vordergrund seines Interesses. In Nürnberg, wo Pirkheimer für Geschichte wirkte, wo ihn geschichtliches Leben umgab und er den humanistischen Geist in vollen Zügen einsog, weitete sich ihm die Seele aus. Er entwarf nun den Plan seiner Cniversalhistorie, dicse wurde dann in Strassburg gedruckt, es folgten seine Kosmographic, seine deutache Geschichte und seine Sprich-

*5 Vgl. bewonders Keller, ein Apostel der Wiedertäufer S. 131. 133 f. $187 \mathrm{fr}$. Verwande in der Opposition (Ilagen, Reformation $111267 \mathrm{ff}$.) der Nürnberger Ratbstserr fürer, (Ulgen III 290 ) Kauz, (llagen 11 I 306) Vünderliu. 
wörtersammlung. Aber darin bestand nun gerade seine Bedeutung, dass er durch die Ideen dieser deutschen Reformzeit Leben und Zusammenhang in den geschichtlichen Stoff der Chroniken brachte und dass ihm dann in diesen universellen Zusammenhang auch das Historische der Bibel sich einordnete: so wurde die heilige Geschichte unter ganz originalen Gesichtspunkten von ihm aufgefasst. Die religiösen Broschüren, in denen er diese Gesichtspunkte entwickelte, voran die genialen Paradoxa, mussten den Konflikt dieser Position zu der sich bildenden Kirche Luther's erweisen. Auch in den religiös freieren Reichsstädten, in Nürnberg, Strassburg, Olm fand der von den Sekten sich fernhaltende Denker keinen Ruheplatz. Er stand ausserhalb aller christlichen Confessionen, „unparteiisch" wie er sich ausdrückt, darin dem Spinoza zu vergleichen. Von den Methoden der neuen Luther'schen Orthodoxie, unter milden, brüderlichen Worten das in der Kirche eingewohnte Verfolgungsbedürfniss zu befriedigen, wurde ihm, der doch, bei mancher persönlichen Berührung mit Schwenkfeld und den Täufern, ausserhalb des ganzen Parteigetriebes stand, die Seele wundgerieben und das Leben vergiftet. $\mathrm{Er}$ ist in frühen männlichen Jahren müde dahingegangen.

Der religiös universalistische Theismus oder Panentheismus, von den Alten, besonders von der in der römischen Stoa vorliegenden letzten und menschlich höchsten Form ihres Denkens getragen, war damals das höchste und freieste Element der europäischen Bildung. Er ist nun auch der Gesichtspunkt, unter welchen Franck die von ihm innerlichst miterlebte deutsche religiöse Bewegung, von Tauler und der deutschen Theologie bis auf Luther, Zwingli und die Täufer, gestellt hat. Die Unsichtbarkeit, Innerlichkeit, Bildlichkeit des moralisch-religiösen Processes, das Streben, ihn von den egoistischen Bestandtheilen der vulgären Religiosität loszulösẹn, die Erkenntniss der Unverträglichkeit dieses Vorgangs mit jedem kirchlich regimentalen Verbande: diese, wenn man will, spiritualistische Richtung der deutschen Reformationsbewegung wird von ihm mit einer ruhigen Klarheit durchgeführt, die den Sektenhäuptern fehlte. Ihm stand nun eine zwar nicht gründliche, aber ganz umfassende universalgeschichtliche Uebersicht für die Durchführung dieses Stand- 
punktes zur Verfügung. 'So musste die Consequenz desselben in universalgeschichtlicher Richtung deutlicher hervortreten. War der Glaubensprocess das Centrum des persönlichen Daseins, so musste er auch der Mittelpunkt der Geschichte, das Verbindende in ihr sein. War er nur innerlich, in dem Verhältniss des Menschen zu der unsichtbaren Ordnung, bedingt, dann war er auch unabhängig von Zeit und Ort und überall in der Geschichte der Menschheit gegenwärtig. Die unsichtbare Kirche hatte dann ihre Glieder auch in den Zeiten vor Christus und und unter den Glaubensformen der Juden, Türken und Heiden aller Art. Der religiös universale Panentheismus hatte nun also in Franck die Aufgabe zu lösen, als „Bindriemen ${ }^{*}$ der Universalgeschichte und als Kern der biblischen Theologie seine Fruchtbarkeit für diese beiden Wissenschaften zu erweisen.

Wir beginnen mit dem Begriff Gottes. Auch bei ihm ist derselbe nicht philosophisch abgeleitet, sondern aus freier Reflexion gewonnen. Es ist der damals über Europa verbreitete, durch das fortschreitende Naturstudium und die Alten geläuterte Panentheismus. Franck fasst Gott wie Zwingli als das all wirksa me Gute. Gott ist willenlos, affektlos, begierdelos, ihm allezeit gleich, durchaus gut $^{63}$ ). Besonders in der Schrift von menschlicher Kunst und Weisheit entwickelt er diesen Begriff. „Die Natur ist nichts Anderes, denn die von Gott eingepflanzte Kraft eines jeden Dings, Beides, zu wirken und zu leiden. Gott ist allerwegen in der Natur, er erhält die Struktur der Welt mit seiner Gegenwärtigkeit und Innensein. Gleich wie die Luft alles erfüllt und doch an keinem Orte beschlossen ist, wie der Sonne Schein allenthalben ist, den ganzen Erdboden überleuchtet und doch auf Erden nicht ist und doch ist, so gar, dass er alle Dinge auf Erden grünen macht, also ist Gott in Allem und wiederam Alles in ihm beschlossen." „Gott ist cine freiausgegossene Güte, wirkende Kraft, die in allen Kreaturen weset " "). Das Wesentliche ist, dass dio von der Luther'schen Rechtfertigungslehre geforderte Zerlegung des göttlichen Wesens in

c) Paradoxun $3 \mathrm{\pi}$.

4) Paradoxon $23-31$. 
Zustände und Seiten von ihm als unvereinbar mit. dem gedankenmässig aufgeklärten Gottesbewusstsein erkannt wird. Etiam fulminans Jupiter bonus ${ }^{65}$ ). 'Der unbewegliche Gott zürnt über Niemand.

Dies religiöse und philosophische Bewusstsein absoluter Abhängigkeit findet der unbefangene Sinn Sebastian Franck's mit seinem höchst energischen an den Alten bestätigten Bewusstsein von der moralischen Unabhängigkeit des Menschen vereinbar. Dem einseitigen religiösen Tiefsinn der beiden Reformatoren gegenüber macht er mit Erasmus das moralische Bewusstsein geltend. „Wäre kein freier Wille und müsste absolute also Alles geschehen, wie Gott wollte, so wäre keine Sünde, alle Strafe unbillig und alle Lehre vergebens und ein Affenspiel, dass Christus über die Pharisäer trauert u. s. w.". Die in dem Verhältniss dieser Freiheit zum Allwirken Gottes liegende für den Intellekt metaphysisch unauflösbare Schwierigkeit hat er durch den Begriff einer sich selbst freiwillig einschränkenden, den Willen aus sich in die Freiheit der Wahl entlassenden, aber das äussere Wirken dem Zusammenhang einer teleologischen Ordnung einordnenden Kraft Gottes auflösen zu können geglaubt. . „Der Vogel singt und fliegt eigentlich nicht, sondern wird gesungen und in den Lüften dahingetragen. Gott ist es, der in ihm singt, lebt, webt und fliegt. Alle Creaturen thun nur, was Gott will. Diesen Unterschied hat es aber mit dem Menschen, diesem hat er freien Willen gegeben und.will ihn mit diesem führen und ziehen ${ }^{66}$ )." Die Gottheit, selber affektlose, zeitlose, wirkende Kraft, wird erst in dem Menschen Wille. In diesem ist die Kraft in der Zeit verlaufend und in Affekten beweglich. Der Wille ist frei in seiner Wahl, aber sein Wirken in der Welt ist durch Gottes Kraft bedingt, die den Weltzusammenhang bestimmt. Und zwar verwendet die Kraft der Gottheit jede Willensentscheidung zum Guten. Die Aufkäufer und Geizigen in den Städten, die von ihrem Egoismus getrieben handeln, dienen doch dem wirthschaftlichen Interesse des Ganzen.

Aus, der Wechselwirkung der göttlichen Kraft mit'dem freien,

65) Paradox. 53.

66) Paradox. 264-268, gegen Luther de servo arbitrio gerichtet. 
individuellen Menschenwillen entsteht der Zusammenhang der Historie. Ihr Kern und Schlüssel ist der sittlich religiöse Process.

Derselbe beruht auf dem Antagonismus zwischen dem moralischen Prinzip der Menschennatur, das in Gott gegründet ist, und dem Prinzip der Selbstsucht, das aus dem freigelassenen Willen stammt. Dieser Antagonismus wird im Sinne Taulers und der deutschen Theologie ron Franck aufgefasst. Wie er von ihm wiederholt dargestellt ist, ist es leicht in einem seiner Bücher eine Darstellung nachzulesen. Ich hebe hier nur den für den Fortschritt entscheidenden Punkt hervor. Es ist das die Stelle des Systems, an welcher es Kant's Religionsphilosophie vorbereitet.

Ich meine seine eigenthümliche Lehre von Christus. Es giebt eine allen Nenschen eingeflanzte moralische Anlage. In Uebereinstimmung mit der Stoa und Cicero erklärt Franck es für die nächste Aufgabe des Menschen, der Natur oder Gott zu folgen und erkennt ein "Licht der Natur* (lumen naturale) in Jedem an, welches dies ermöglicht. Dies Licht der Natur ist allen Menschen gemein, dass ein Jeder das Urtheil in seinem Busen stecken hat. So erklärt er auch die Vernunft für einen „Brunnen aller menschlischen Rechte, deshalb über alle geschriebenen Rechte ${ }^{467}$ ). Was nun Plato, Seneca, Cicero und alle erleuchteten Heiden das Licht der Natur und die Vernunft genannt haben, das bezeichnet die Theologie als das Wort, als den Sohn Gottes und als den unsichtbaren Christus. Dieser ist so gut in Seneca und Cicero gewesen als in Paulus. Hiernach versteht er unter Christus (Logos) die Immanenz der sittlich religiösen Ideen in Gott und deren Wirken und sich Mittheilen an die Menschen.

Soll dieser unsichtbare Christus in uns zur Herrschaft gelangen, so muss der Adam in uns, die Selbstsucht, überwunden werden. .Als cin Philosoph gefragt wurde, wann er angefangen habe, ein Philosoph zu werden, antwortete er, da ich mir selbst anfing, ein Freund zu werden. Wenn man einen Christen fragte, wann er cin Christ geworden, würde er antworten: da ich mir selbst anfing Feind zu werden."

6) Paradox. 247. 248. 
Der sittlich religiöse Process besteht also darin, dass der Antagonismus von Fleisch und Geist, von Selbstsucht und natürlichem Licht, der in jedem Menschen ist, durch eine als Wiedergeburt in der Schrift bezeichnete Revolution überwunden wird. Dann ist „die Abnegation, Odium sui, Renunciatio“ des selbstsüchtigen Willens von Allem, was er ist und hat, vollzogen, und der unsichtbare Christus zur Form und Regel des Lebens erhoben. Dieser Vorgang ist ganz universell. Er ist gar nicht an die Bedingungen einer temporal und local eingeschränkten äusseren Offenbarung gebunden, sondern allein an die universale Offenbarung in dem Christus, der nichts als die göttlich immanente moralische Anlage des Menschen ist. Die Paradoxie dieses Satzes steigert sich noch. Franck setzt die Formel von einer ganz allgemeinen Rechtfertigung vor Gott durch den unsichtbaren Christus für die eben gegebene ein. Indem er, mit Erasmus den Inhalt des Glaubens in das, was Christus durch Wort und mehr noch durch Vorbild lehrt, verlegt, entsteht diese totale Umdeutung der Rechtfertigungslehre aus einem objektiv in Gott stattfindenden in einen subjektiven Bewusstseinsvorgang. In der zeitlosen, affektlosen, dem Wechsel der Zustände entnommenen Gottheit ist die Vergebung der Sünden vor dem Falle enthalten; Gott ist immer gnädig. Der unsichtbare Christus belehrt immer die Menschen und theilt ihnen die Form seines Lebens mit. Das Erscheinen Christi im Fleisch hat nur den Menschen gleichsam den Himmel aufgethan und ihnen den gnädigen Gott gezeigt. Sie hat ihren Irrthum über den Zorn Gottes aufgehoben. Sie hat den inneren unsichtbaren Christus, dessen Wesen die Liebe ist und der in jedem höheren Bewusstsein eines Menschen wohnt, von aussen in Vorbild und Lehre sehen lassen. Eben so universell sonach als der. Fall des Menschen in Selbstsucht ist seine Rechtfertigung vor Gott durch Christus.

Aus diesen in der Mystik angelegten, doch erst durch den römisch-stoischen sowie den humanistischen Theismus entbundenen Sätzen leitet nun Franck Consequenzen ab, durch welche er Vorläufer oder Begründer der modernen Religionsphilosophie geworden ist. In hundert Rinnsalen fliessen die Ideen Franck's der modernen Zeit entgegen. 
Das Geschichtliche der heiligen Schriften, sofern es ein einmaliges Geschehen enthält, ist der symbolische Ausdruck, der Typus für einen überall und zu allen Zeiten im Menschengeschlechto sich vollziehenden Vorgang, nämlich den religiös sittlichen in jedem einzelnen Menschen. „Vita una et eadem omnibus. Es ist Ein gleich Leben auf Erden. Omnis homo unus homo. Allo Menschen, Ein Mensch. Wer Einen natürlichen Nenschen sieht, der sieht sie alle." Es ist Alles Adam. Findet man andere Sitten, Sprache und Kleidung, so ist doch das Gemüth, Herz, Sinn und Wille in allen gleich. Der Türke will unter seinem Spitzhut dasselbe als der Deutsche unter seinem breiten Barett. Adam und Christus sind der Ausdruck des Antagonismus in der Menschenatur, der überall derselbe ist. Sündenfall und Erlösung sind der Ausdruck eines ewigen inneren Geschehens. „Die Schrift ist eine ewige Allegorie. “ Denn fasst man sie nach dem Buchstaben, so könnte man eben so leicht Ovids ars amandi vertheidigen. Der Türke beruft sich auf seinen Alcoran, der Jude auf seinen Talmud, der Papst auf sein Dekret, alle auf Schriften, jeder schilt den anderen Ketzer: „darum gedenke ein Jeder, dass die Anderen auch Schrift führen". Wäre ein in der Nitte der Geschichte aufgetretener Vorgang und seine Aneignung durch die Schrift die Bedingung der Rechtfertigung und Seligkeit, dann wären alle verdammt, an relche das äussere Wort nach den räumlichen und zeitlichen Verhältnissen nicht gelangen konnte. Daher muss die Rechtfertigung der in Adam Gefallenen durch Christus als ein von Zeit und Ort und äusseren Bedingungen unabhängiger innerer, unsichtbarer und universeller Vorgang aufgefasst werden.

Welches Verhälniss zu diesem ewigen Geschehen hat nun der in der beiligen Schrift berichtete Zusammenhang der äusseren Vorgänge? Die altere allegorische Schriftbehandlung trennt sich hier von der Religionsphilosophie Kant's und seiner Nachfolger. Dio Annahme, dass die Schrift einen doppelten Sinn habe, ist streng von der zu unterscheiden, dass ewige Wahrheiten in geschichtlichen Symbolen sich ausdrücken, denen dann keine bistorische Geltung zukommt. Dicse letztere Annahme kann zwar nicht auf die ganze biblische Historic und Theologic angewandt werden, und ist auch 
von keinem besonnenen Forscher so angewandt worden. Denn es giebt in derselben genug historische Thatsachen, die kein Zweifel berührt. Nur der Umfang derselben ist streitig. Aber dass sich an diese Thatsachen Symbole d. h. sinnliche Bilder innerer und ewiger Wahrheiten angeschlossen haben, denen keine historische Gültigkeit zukommt, dass es Dogmen giebt, welche innere Wahrheiten zu äusseren objektiviren, dass es Erzählungen giebt, welche ein ewiges Geschehen in die Form eines einmaligen, zeitlichen kleiden: wer darf das heute bestreiten? Und diese Einsicht ist nach manchen einzelnen Aperçus der Humanisten zuerst in umfassender Weise von Sebastian Franck zur Geltung gebracht worden.

Der zeitliche Verlauf von Sündenfall, Zorn Gottes und Rechtfertigung des Menschen vor Gott durch den Opfertod Christi ist für Franck ein Symbol für ein zeitloses. Dieses Symbol lehnt sich an die geschichtlichen Thatsachen der Evangelienerzählung, welche Franck keinem Zweifel unterwirft. Die geltende Rechtfertigungslehre verlegt einen menschlichen Bewusstseinsvorgang, in welchem der Irrthum über Gottes Verhalten zum Menschen sich auflöst, in die Gottheit selber. „Die Historie von Adam und Christo sind nicht Adam oder Christus. Deshalb wie viel in allen Winkeln und Inseln Adain sind, ob sie gleich nicht wissen, dass je ein Adam auf Erden gewesen, also sind auch unter den Heiden zu aller Zeit Christen gewesen, die auch nicht wissen, ob je ein Christus gewesen oder sein wird. Ich glaube, dass beide, Christus und Adam in allen Menschenherzen sei, der äusserliche Adam und Christus ist nur ein Ausdruck des innerlichen inwohnenden Adams oder des ewigen Christi, der in Abel ist getödtet" ${ }^{68}$ ).

So steht Franck dicht vor dem Problem der Vorstellungsbildung, in welcher das Unsichtbare und Innerliche jeder Religion und Theologie symbolisch zu Bildern von Objektivem, Aeusserem und Zeitlichem vergegenständlicht wird. Auch hat ihn seine universal-historische Betrachtung 'schon cinzelne tiefe Blicke in' die Kräfte thun lassen, aus denen diese Vorstellungsbildung entspringt.

Franck's Universalhistorie ist, wie Bischof im Einzelnen nach-

68) Paradox. 231, zusammengezogen. 
gewiesen hat, auf der Grundlage der Chronik des Nürnberger Arztes Schedel so aufgebaut, dass ein paar Dutzend Quellen und andere Bearbeitungen zur Ergänzung hinzugezogen sind ${ }^{69}$ ). Die Hilfsmittel und Methoden der philologisch-historischen Kritik sind ihm unbekannt. Aber sein Buch überschreitet die vorangegangene Historie, weil es das grosse Hilfsmittel der Reformationszeit, das intimste Gefühl für die wirkenden Kräfte der Religionsgeschichte, dazu benutzt, einen inneren Zusammenhang in der Geschichte herzustellen, welcher dem Reformationszeitalter angemessen war und die mittelalterliche Universalhistorie hinter sich liess. Ein weiter, unbefangener Blick, ein männliches, wahrhaft volksmässiges Deutsch, ein muthiges Herz haben seinen historischen Ideen Verständlichkeit und nachdrückliche Wirkung auf die Nation wie auf die nachfolgenden Schriftsteller gegeben.

Franck geht wie die mittelalterliche Universalgeschichto von dem Bewusstsein eines inneren teleologischen Zusammenlangs der ganzen Geschichte aus. Er will ${ }_{n}$ den Haft, Satz, Inhalt, Kern und Bindriemen der Historie anzeigen", überall das "Eigentliche* hervorheben und die "Historie mit den Ursachen beschreiben“. Aber dieser Zusammenhang kann ihm nicht in der äusserlichen und zeitlich verlaufenden Oekonomie des Heils gelegen sein: gleichsam in der Längenrichtung der Geschichte. Er liegt ihm in den immer vorhandenen Verhältnissen der inneren Erfahrung zwischen der Selbstsucht, dem unsichtbaren Christus und dem Wirken der Gottheit. Er will erkennen, wie aus diesen inneren Verhältnissen immer dieselbe äussere Form der Welt, Staaten, Fürsten, Sekten, Dogmen, Ceremonien hervorgehen, ihre einzelnen Gestalten „einherstolziren" und sich auflösen, dabei aber die Gestalt der Welt immer im Grunde dieselbe bleibt. Er betrachtet den Zusammenhang der Geschichte gleichsam in der Tiefenrichtung. Er erforscht, wie in ihm aus den immer wirksamen Kräften die Formen des geschichtlichen Lebens sich gestalten. Wie er in seiner Gesinnung mit Schlowiser verwandt ist, so in dieser grossen Intention mit Giovanni Battista Vico.

cy Bischof, Selantian Franck und deutscbe Geschichtsschreibung. 1857, bes. $\mathrm{S}$. $11 \mathrm{f}$. 
Gott setzt sich nach seiner Wesenhaftigkeit in der Geschichte durch. Die Sünde ist nur ,ein unnützer Conat und die Unterfangung eines Dings, das man gern thäte und nicht thun kann ${ }^{* 70}$ ). Sie macht sich als Begierde und selbstsüchtige Intention geltend, sonach als freie Ursache; ihre Wirkungen aber sind in den Wirkungszusammenhang, welcher dem Guten dient, aufgenommen. Der Tyrann will, begehrt und handelt frei, in verantwortlich eigener Selbstsucht, aber in seinem Wirken ist er das Werkzeug Gottes. Die Geschichte ist überall von der Selbstsucht und Beschränktheit der Menschen durchwirkt; diese wird überall den inneren religiös sittlichen Process veräusserlichen, dem Herrschaftswillen ihn in äusseren Ordnungen unterwerfen ihn und in Ceremonien versinnlichen. Der Wechsel ihrer grossen Gestalten entsteht aber, indem jede derselben sich nach der in ihr enthaltenen Selbstsucht und Beschränktheit in ihr Nichts wieder auflöst. Die Grundstimmung des Geschichtsschreibers ist tragisch zugleich und satyrisch oder humoristisch, erfüllt von der tiefen Ironie der Weltgeschichte. So sagt er von der ihn umgebenden Gegenwart: „Wer diese Sache mit Ernst ansieht, dem wäre nicht Wunder; dass ihm sein Herz zerbreche vor Weinen. Siehet man's wie Demokrit schimpflich an, sollt einer vor Lachen zerknallen. So gaukelt die Welt.“ "Wir sind alle Gelächter, Fabel und Fastnachtspiel vor Gott." Luther wirft ihm sein eiferndes Schelten vor, wie man es Schlosser vorgeworfen hat. Er nennt wohl die Welt nicht nur ein wüstes Babylon, sondern einen Saustall. Er empfindet tief die tragische Ironie, wie Gott die einzelnen Gestalten der Welt, die nicht aus ihm kommen, "hoch aufsteigen lässt“ und dann "vor ein spöttliches Ende bringt“. „Die Römer haben ihren Lauf, Sieg und Zeit gehabt, darinnen ihnen Niemand hat können widerstehen und sie alles gebeugt und unter sich gebracht. Sobald sie ausgedient hatten, ist beides, Herz und Reich - und alles hingegangen wie her ${ }^{71}$ ).“

In diesem Zusammenhang steht nun seine universalhistorische Ansicht von der Religion. Das innere Licht ist in Plotin, Diogenes,

70) Paradox. 31.

71) Kosm. 163a. 
Plato, Orpheus, Sophokles und den Sybillen so gut als in den biblischen Personen. Aber eben so universell ist, aus dem Eigenwillen des Menschen und seiner Eingeschränktheit, ja seiner Narrheit entspringend: die Veräusserlichung des Innern, der Herrschaftswille über das Freie in äusseren Ordnungen, die Zerspaltung der Einen religiösen Wahrheit in Sekten und deren Religionsbegriffe und die Versinnlichung des unsichtbaren Vorgangs in Ceremonien. Und zwar sind der Bösen und der Narren mehr als der Frommen, die letzteren sind in der religiösen Gesellschaft nur spärlich unter die anderen gemischt. ,Man mach es - dies ist der tiefste schwermüthige Ausdruck seiner Lebenserfahrung - wie man wolle, so muss die Welt ein Papstthum haben, denn sie reiss sonst nicht wo aus und was sie thun soll. Die Welt will und muss einen Papst haben, dem sie zu Dienst wohl alles glaube, und sollte sie ihn stehlen oder aus der Erde graben, und nehme man ihr alle Tage einen, sie sucht bald einen anderen. ${ }^{*}$ Aus derselben Menschennatur entspringt, dass „die Welt von keinem anderen Gottesdienst weiss, als dem äusseren ceremonischen, Singen, Wallen, Beten, Kirchengehen, Fasten, Bildern".

So gehen ihm nun auch grosse Ansichten darüber auf, wie die Epochen der Religionsgeschichte von einander abhängig sind. So geht er dem nach, wie die päpstliche Kirche aus den Institutionen des Imperium hervorgewachsen. „Die römischen Pfaffen hatten auch einen Papst, den sie pontifex maximus nannten.“ „Bei den Heiden hatte jeder Gott seinen Pfaffen; Flamines, Vorsteher und Tempelknechte, die die Götzen ausputzten, die Kirchen zierten, der Lichter warteten, die heiligen Zeiten und Feste rerkündigten ${ }^{472}$ ). Dieselben Tempel, Priester und Ceremonien gehen durch die ganzo Religionsgeschichte in einer Continuität, die er bis auf die Egypter im Einzelnen rückwärts verfolgt. Alles Schatten und Figuren des inneren Wortes.

Lnd er selbst? Der Geschichtsschreiber, der dies Gaukelspiel der Welt unparteiisch betrachtet? Auf dem dunklen llintergrund all dieser Verfolgungen, Torturen und Ilinrichtungen von Täufern

is G. B. $494 a$. 
und Spiritualisten, der officiellen Lügen protestantischer und katholischer Kirchenhäuptlinge, der Enttäuschungen über den Gang der Reformation erhebt sich der moralisch religiöse Pessimismus des Sebastian Franck: wie ein schwermüthiges und doch tief beschauliches Antlitz, dessen Augen sich einzubohren scheinen in dies Meer von Gram und Unrecht. Dieser Mann ist einsamer noch als nachher Spinoza. Er fühlt sich innerlich losgelöst von allen S̈ekten, in welche die Eine Wahrheit zerrissen ist, daher gehört er keiner gegenwärtigen und wartet keiner neuen äusseren Kirche. Ein Glied der. unsichtbaren Gemeinde, der schon Sokrates und Seneca angehörten. $\mathrm{Zu}$ ihr gehören alle "gottfrommen. gutherzigen Menschen“, ohne Ceremonien und äusseren Gottesdienst. „In und bei dieser Kirche bin, zu der sehne ich mich mit meinem Geist, wo sie zerstreut unter den Heiden und Unkraut umfähret" ${ }^{63}$ ). Wer denkt nicht an Lessing's einsames Ende in Wolfenbüttel, an das Christenthum seines Testamentes' Johannis und seiner Erziehung des Menschengeschlechtes?

73) Paradox., Vorrede. 